\title{
REVIEW ARTICLE OPEN \\ A comparative review of the aqueous corrosion of glasses, crystalline ceramics, and metals
}

\author{
Gerald S. Frankel (iD), John D. Vienna², Jie Lian ${ }^{3}$, John R. Scully ${ }^{4}$, Stephane Gin ${ }^{5}$, Joseph V. Ryan ${ }^{2}$, Jianwei Wang ${ }^{6}$, Seong H. Kim (iD), \\ Wolfgang Windl ${ }^{1}$ and Jincheng $\mathrm{Du}$ iD $^{8}$
}

All materials can suffer from environmental degradation; the rate and extent of degradation depend on the details of the material composition and structure as well as the environment. The corrosion of silicate glasses, crystalline ceramics, and metals, particularly as related to nuclear waste forms, has received a lot of attention. The corrosion phenomena and mechanisms of these materials are different, but also have many similarities. This review compares and contrasts the mechanisms of environmental degradation of glass, crystalline ceramics, and metals, with the goal of identifying commonalities that can seed synergistic activities and advance the current knowledge in each area.

npj Materials Degradation (2018)2:15; doi:10.1038/s41529-018-0037-2

\section{INTRODUCTION}

New research activity focused on the environmental degradation of silicate glasses, crystalline ceramics, and metals relevant to nuclear waste forms and containers has recently been described. ${ }^{1}$ The premise is that synergistic interactions between experts in the corrosion of these different material classes will lead to advances in understanding that would not otherwise have been possible. One of the commonalities associated with the corrosion of glasses, ceramics, and metals is the formation of a thin surface layer, called an alteration layer or a passivating film, which may provide protection from environmental degradation. A key aspect of the corrosion resistance of each material is whether the film is a barrier to or is susceptible to corrosion when subjected to a mixture of driving forces that challenge the integrity of the layer. This paper reviews the basics of the corrosion and protection mechanisms of these surface films first individually for glass, ceramics, and metals, and then draws conclusions regarding the similarities and differences in these surface films, their formation and breakdown, and the roles they play in the corrosion and protection processes. The focus of this review is on examples of glasses, crystalline ceramics, and metals that are of primary interest to nuclear waste management. Therefore, examples of each materials class are discussed: boro-silicate and alumino-borosilicate glasses, aluminosilicate and titanate ceramics, and corrosion-resistant metallic alloys. Cementitious materials are also used extensively in waste immobilization, both for encapsulation or backfill and as a waste form for low level waste, but this review does not address the degradation of cement.

\section{OVERVIEW OF SILICATE GLASS CORROSION}

Although most of this section applies to all kinds of silicate glasses, the focus is on borosilicate glass of nuclear interest. Waste glasses are made of an alumino-boro-silicate network partly depolymerized by network modifiers. Actual waste glass contains tens of different oxides, but researchers have also investigated simpler versions of these materials. At the micrometer scale these glasses are considered to be chemically homogeneous. At much smaller scales $(<1 \mathrm{~nm})$ they display a short-range order like crystals, but this structural organization vanishes above the nanometer scale.

The primary mechanism responsible for the release of radionuclides from nuclear waste glass is through reactions of the glass with the aqueous environment in the disposal facility. The resistance of glass to aqueous corrosion, termed glass durability, is not solely an intrinsic property of the glass, but is rather the response of glass to a range of environmental factors. ${ }^{2}$

The reactions between alkali-boro-silicate waste glass and water include: (1) ion exchange between ionic species in water (particularly $\mathrm{H}^{+}$) and ionic components in the glass (primarily alkali); (2) hydrolysis of network forming species (e.g., silica, boria, and alumina tetrahedra); and (3) dissolution of hydrolyzed species into solution. Through these three primary reactions, glass components are released to solution and/or are incorporated into alteration products (amorphous and crystalline phases) on the reacting glass surface. The rates of the reactions are controlled by many factors. Chief among them are temperature, solution $\mathrm{pH}$, and concentration of dissolved solution species (e.g., $\mathrm{H}_{4} \mathrm{SiO}_{4}$ and $\left.\mathrm{Al}(\mathrm{OH})_{4}{ }^{-}\right)$. These processes are summarized in many recent reviews. ${ }^{2-10}$

The processes of ion exchange, hydrolysis, dissolution, and alteration product formation are coupled, primarily through the chemistry of the solution contacting the glass and the properties of the amorphous layer, which may limit transport of water and ions to and from the reacting glass surface. The combination of corrosion mechanisms results in component release and reaction progress behavior with three characteristic stages that are characterized in Fig. 1. When bare glass is exposed to dilute

\footnotetext{
${ }^{1}$ The Ohio State University, Columbus, OH, USA; ${ }^{2}$ Pacific Northwest National Laboratory, Richland, WA, USA; ${ }^{3}$ Rensselaer Polytechnic University, Troy, NY, USA; ${ }^{4}$ University of

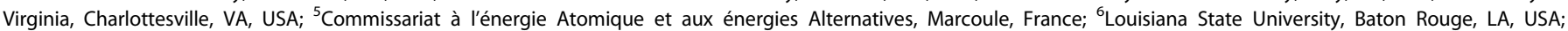
${ }^{7}$ Pennsylvania State University, University Park, PA, USA and ${ }^{8}$ University of North Texas, Denton, TX, USA Correspondence: Gerald S. Frankel (frankel.10@osu.edu)
} 


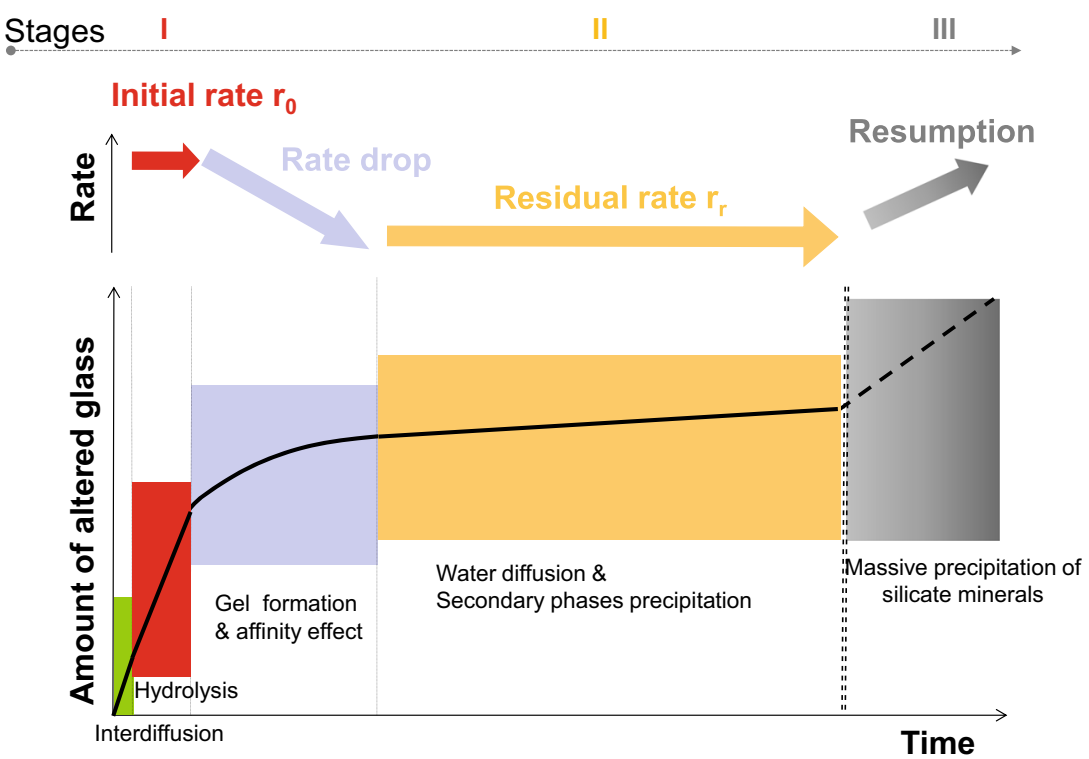

Fig. 1 Stages of nuclear glass corrosion. (Reproduced with permission from ref. ${ }^{6}$, copyright Elsevier 2013)

solution, the process begins by corrosion of the glass surface with no solution feedback at an initial rate of $r_{0}$ (sometimes called the forward rate). This period, termed Stage I, produces a rate that is a maximum for the given temperature and $\mathrm{pH}$; it is controlled by hydrolysis of network forming species. As the concentration of glass formers in solution increases, the driving force for dissolution decreases, and alteration layers begin to form. The change in mechanistic drivers leads to a nearly constant and slow residual rate $\left(r_{r}\right)$ during a period termed Stage II. Depending on environmental parameters, certain alteration products may eventually form that deplete the solution of glass formers and lead to an acceleration of the release rate to $r_{\text {III }}$ during Stage III.

The time that the glass remains in each stage depends strongly on environmental parameters that impact the rates of individual reactions (e.g., temperature, $\mathrm{pH}$, solution composition and flow, glass composition). In fast flowing environments, the solution remains dilute and Stage I dominates for long periods that might be unlimited. In slow flowing or static conditions, Stage II is quickly achieved. It is also worth noting that the associated $r_{\mathrm{r}}$ appears to best represent the behavior of ancient natural and man-made glasses that have been exposed for thousands to millions of years. ${ }^{11,12}$ Stage III has been identified in selected systems when large amounts of secondary phases such as calcium-silicate hydrates $(\mathrm{CSH}){ }^{13}$ magnesium silicates, ${ }^{14-17}$ iron silicates, ${ }^{18-21}$ or aluminosilicate zeolites ${ }^{22-25}$ precipitate. However, Stage III corrosion has not always been observed, with some systems exhibiting slow alteration rates representative of Stage II behavior for long periods of exposure.

Formation of alteration layers and potential-passivating mechanisms

Although it is well established that silica-rich surface layers formed on nuclear glass surfaces can be transport limiting, ${ }^{26,27}$ the detailed processes by which the alteration layers form and ratelimiting reactions or phenomena attributed to the layers are still under debate. ${ }^{28}$ Generally, highly dense and silica-rich amorphous interfacial layers are efficient barriers to water and ion transport, ${ }^{27,29}$ but the alteration layers formed on glass are often not dense. Rather, silica from the glass, along with other glass components such as $\mathrm{Al}, \mathrm{Zr}$, and $\mathrm{Ca}$, or exogenous elements supplied by the solution, form an amorphous, porous, and hydrated interfacial surface layer by one of two processes: (1) reorganization via hydrolysis/condensation reactions in which $\mathrm{SiO}_{2}$ tetrahedra are not completely detached from the glassy network and/or (2) dissolution and reprecipitation of species in the aqueous solution. ${ }^{30,31}$ The relative importance of these two processes depends on the glass composition, on the $\mathrm{pH}$, and more generally on the solution composition. There is still uncertainty in the domains over which the two processes dominate; however, it currently appears that dissolution/precipitation dominates under conditions far from saturation (dilute condition, very acidic, or very alkaline $\mathrm{pH})_{1}^{32-34}$ whereas in situ reorganization accounts for the formation of the surface layer when the solution is nearly saturated in silica. ${ }^{35,36} \mathrm{~A}$ recent model suggests that dissolution/ precipitation reactions take place at the glass surface. ${ }^{37}$ However, this model is challenged by recent isotopic evidence showing that, in neutral or slightly basic $\mathrm{pH}$ conditions and in silica-saturated conditions, the alteration layers formed on a simplified waste glass is almost completely built by in situ reorganization of the glassy network from which weakly bonded species have been removed and silica is hydrated. ${ }^{36}$ It is likely that both mechanisms play a role under different conditions.

Initially, it was thought that the alteration layer acted as a diffusion barrier for silica or water, but the initial kinetic models derived from this idea ${ }^{38,39}$ poorly represented the observed $r_{\mathrm{r}}$ values. $^{40-42}$ It is apparent that simple diffusivity is not adequate to address the mechanism of passivation. For example, porosity closure within the amorphous layer was observed for certain glasses after a large extent of reaction. ${ }^{43,44}$ This phenomenon requires the breaking of bonding oxygen to maintain glass alteration and could thus account for very low apparent diffusion coefficient of mobile species through passivating layers $\left(10^{-20}\right.$ to $\left.10^{-23} \mathrm{~m}^{2} \mathrm{~s}^{-1}\right) .^{36,45}$ In the absence of porosity closure, which has been observed in some cases, it was proposed that the nanoconfinement of water molecules within pores of $\leq 1 \mathrm{~nm}$ diameter could slow down the access of water to the pristine glass surface. $^{36}$ Some experimental evidence supports this theory, although its general applicability has not been proven. The structure and properties of the porous interfacial layer depends on both the glass ${ }^{46}$ and solution ${ }^{34,47,48}$ compositions, particularly the solution $\mathrm{pH}$. It is worth noting that similar conclusions have been made for weathering of silicate minerals with major implications in geochemical cycles. $^{49}$ 


\section{Breakdown of passivation}

The protective passivation mechanisms can change over time as conditions change and the alteration layers evolve. The alteration films are amorphous, which means that they are thermodynamically unstable and can, according to the Ostwald rule of stages, dissolve, ripen, or crystallize, as observed in natural glasses. ${ }^{50}$ The crystallization of secondary phases also occurs through direct precipitation from solution. These processes can both occur progressively if crystallization is kinetically slow. Such a phenomenon can result in the loss of any protective properties of the interfacial layer and change the geochemical properties of the solution in contact with the uncorroded glass, either of which in turn can lead to accelerated glass dissolution rate. Even though it is difficult to accurately determine the underlying mechanisms due to the multiple acting variables, a general mechanism can be proposed based on the nucleation and growth of zeolites that consume the network forming elements $\mathrm{Si}$ and $\mathrm{Al}$ from the alteration layer. ${ }^{51}$ To a lesser extent, precipitation of $\mathrm{CSH}$ can also be involved in similar disruptions. ${ }^{34}$

Zeolite precipitation, with detrimental consequences for glass durability, has typically been seen in laboratory experiments performed at high $\mathrm{pH}$ (generally above $\mathrm{pH}_{90}{ }^{\circ} \mathrm{C}$ 9.8), either resulting from an external source of alkalinity or for high alkali content glasses and at high temperature $\left(\geq 70^{\circ} \mathrm{C}\right) .^{51,52}$ It is also observed that the extent of the induction period preceding the acceleration (Stage II) decreases with increasing $\mathrm{pH}$ and with seeding of some zeolites, but not others. ${ }^{53}$ Conversely, in the nearneutral $\mathrm{pH}$ and lower temperature conditions representative of most repository environments, it is not known if, over times exceeding laboratory experiments, zeolite formation would disrupt the passivating mechanisms, and increase the glass dissolution rate. This important question was partly addressed in the case of International Simple Glass (ISG) ${ }^{53}$ but requires more work to be generalized. Similar accelerated dissolution has been observed to be concurrent with the precipitation of certain phases resulting from the interaction with near-field ions. This phenomenon will be discussed later.

Other physical processes, such as mechanical stress or radiation damage, could also affect glass passivation. The formation of hydrated surface layers has the potential to generate mechanical stress (i) within the layer itself, forming cracks and thus promoting direct contact between the fluid and the pristine glass surface, or (ii) within the glass, creating fresh surfaces in the pristine material. ${ }^{54-56}$ If fresh surfaces are created, it is then critical to assess if the passivating effect is re-established over time. Except in rare cases, ${ }^{57}$ there is no evidence in the literature for a dramatic increase of nuclear glass alteration due to stress effects. The effects of radiation damage have been intensely studied. ${ }^{58-61}$ However, no experiments carried out on actual nuclear glasses, doped glasses with short live emitters, or externally irradiated glasses show evidence of a potential disruption of the passivating mechanisms under irradiation. ${ }^{59}$ Studies are in progress to see if glasses could exhibit slightly different passivating mechanisms during irradiation with high alpha doses.

\section{Effect of glass composition}

A wide range of borosilicate glasses are being produced internationally due to the variations in waste compositions, vitrification technological constraints, and glass acceptance drivers between vitrification sites. As detailed below, decades of research have shown that glass composition strongly influences glass performance. The four primary impacts of glass composition on glass corrosion behavior are: (1) the structure and properties of the reacting glass, (2) the valence state of multivalent ions in the glass, (3) the structure and properties of alteration products that form by restructuring of the hydrated glass, and (4) the influences on the solution in contact with the corroding glass. It is worth noting that solution composition can be influenced both by the composition of the dissolving glass and by interaction with nearfield materials as described below.

During Stage I, the glass composition effects are dominated by the structure of the reacting glass. lon exchange properties have been directly correlated to glass composition and medium range order. $^{28,62-68}$ Additionally, the driving force to dissolve glass formers and therefore the rate of dissolution are dependent on glass composition., ${ }^{8,69-73}$ During Stage II, the structure and properties of the alteration products will also influence the rate of corrosion. Ribet et al. $^{52}$ reported the effect of many components in glass on the residual rate of glass alteration in pulsed-flow tests at $90^{\circ} \mathrm{C}$. The value of $r_{\mathrm{r}}$ was increased by $\mathrm{K}>$ $\mathrm{Li} \approx \mathrm{B}>\mathrm{Na}$ and decreased by $\mathrm{Al}>\mathrm{Si}>$ Fe. Frugier et al. ${ }^{74}$ identified significant impacts of small composition changes on the $r_{r}$ measured under static conditions. The valence state of multivalent elements within the glass such as transition metal ( $\mathrm{Fe}, \mathrm{Cr}, \mathrm{Mn}$, Tc...), lanthanides or actinides could impact glass durability in different ways. First, the structural role of an element of variable valency can be redox dependent. For instance, $\mathrm{Fe}(\mathrm{III})$ is a glass former whereas $\mathrm{Fe}$ (II) is a glass modifier. A Fe(III) rich glass should therefore be more resistant to degradation even though the difference should be smaller than that induced by a monovalent cation. Second, the reduction/oxidation (redox) potential of the leaching solution can affect the redox reactions during glass corrosion, thus the nature of secondary phases, which, in turn, could impact glass alteration. To use iron as an example again, phyllosilicate iron-silicate precipitation can have a neutral impact on corrosion ${ }^{75}$ while other iron silicates have been shown to have a detrimental effect. ${ }^{18}$ The differences in phase formation are often due to local redox conditions.

The effects of composition on Stage III rates have not been systematically studied, although it has been theorized that these rates may be dependent on the coupled reactions of precipitation of crystalline alteration products and glass corrosion, and so are likely dependent on solution composition and potentially glass structure. ${ }^{76}$ Recent studies have focused on the effects of composition on the triggering of Stage III corrosion. $22,53,77-80$ Clearly, high concentration of alkali elements, which increase $\mathrm{pH}$, sufficient concentrations of $\mathrm{Ca}$ (to form CSH), Al (to form zeolites), $\mathrm{Mg}$ (to form magnesium silicates), or Fe (to form iron silicates) can promote the acceleration of corrosion rate to Stage III behavior, or at least will maintain a high Stage II rate.

\section{Effect of environmental parameters}

As stated above, glass durability is not an intrinsic property of the material but strongly depends on its environment. Various repository environments are under investigation in different countries: steel, concrete or ceramic overpacks, and clay, salt, shale, or granite host rocks. ${ }^{6,81}$ Each design will provide a specific water composition in contact with the glass, thereby affecting its reactivity. The main environmental parameters that are considered to impact nuclear waste glass performance are the water composition, the transport properties both of the near-field and the host rock, and the reaction products of near-field materials (e.g., iron-based or nickel-based metallic alloy container, cement phases, minerals of the host rock) in the vicinity of the glass. For instance, the literature reports several results of a detrimental effect of iron corrosion products on glass because the formation of the passivating layer is delayed or prevented by sorption of $\mathrm{Si}$ onto iron compounds and more importantly by precipitation of iron silicates. ${ }^{18,21,57,82,83}$ Precipitation of silicate minerals is an additive process: in the case of phyllosilicate precipitation, experimentally sustained by the regular supply of $\mathrm{Fe}, \mathrm{Mg}, \mathrm{Ni}$, or Co by the aqueous environment, the alteration rate of the glass increases proportionally to the amount of secondary precipitated phases. ${ }^{84}$ When $\mathrm{Mg}$ is supplied by Mg-bearing minerals, both 
dissolution of the primary phase and transport of reactive species can affect the composition and the thickness of the passivating layer, and thus the alteration rate. ${ }^{15,85}$ The detrimental role of $\mathrm{Fe}$ and $\mathrm{Mg}$ on the long-term behavior of nuclear glass is supported by studies on archeological glasses. ${ }^{18,86,87}$ More data are required (composition, thermodynamic properties, and kinetics of the precipitated phases) to perform a quantitative estimation of the impact of this phenomenon on glass package lifetime. The presence of cement near glass primarily affects the $\mathrm{pH}$ of the solution and triggers the precipitation of $\mathrm{CSH}$ and zeolites as explained earlier.

In summary, glass corrodes via a set of coupled processes involving chemical reactions and transport of reactants and products at various scales. Three main kinetic regimes have been identified, which depend on the glass composition and many environmental factors. A domain of passivation has been identified but the mechanisms responsible for this effect can be disrupted by the precipitation of more stable and non-passivating compounds. To date, available kinetic models only capture part of the known corrosion processes, which limits their predictive capabilities. Nonetheless, based on the current knowledge it seems possible to design nuclear waste disposal for which geochemical conditions are beneficial to achieving and maintaining the passivation of glass waste forms. This typically excludes cement or high amounts of iron in the vicinity of glass canisters. Programs of scientific research are underway around the world to better understand and predict these complex processes. ${ }^{1,6}$

\section{OVERVIEW OF CRYSTALLINE CERAMIC DISSOLUTION}

Crystalline ceramic materials often form at high temperature and become thermodynamically unstable at ambient conditions. Upon contact with water, crystalline materials experience chemical reactions such as hydration, hydrolysis, ion exchange, or redox reactions. Chemical bonds of crystalline oxides exposed in aqueous environments can be broken by aqueous attack, leading to crystal dissolution. ${ }^{88-93}$ The dissolution of ceramics can be either congruent or incongruent. Congruent dissolution can proceed by dissociation of ionic compounds, e.g., in $\mathrm{MgF}_{2}$, or chemical reactions with solvents, e.g., through acid-base reactions or hydrolysis. Incongruent dissolution occurs by selective leaching and non-stoichiometric release of different elements, leaving lesssoluble reaction products forming an alteration layer that is either crystalline or amorphous, similar to incongruent dissolution of glasses. In multi-oxide ceramics as well as in glasses, the ionic potential, which is the ratio of charge to ionic radius, may control the metal-oxygen bond breaking in aqueous solution, leading to very different dissolution rates of the constituent elements. ${ }^{92,94}$ The metal cations with the slowest bond-breaking rate may be left as a residual layer at the interface with the rapidly dissolved cations partitioned to the solution. Ion exchange can also occur, in which mobile ions are leached from the more resistant matrix by exchanging with solution ions, while leaving the matrix more or less intact.

\section{Fundamentals of kinetics of crystal dissolution}

Kinetically, the dissolution of ceramics and minerals is controlled by either transport or chemical reactions at the interface. Figure 2 schematically represents the kinetics of ceramic dissolution. ${ }^{95,96} \mathrm{~A}$ constant leachate concentration with time in a flow-through test indicates surface reaction (matrix dissolution) control. On the other hand, a diminishing leachate concentration with time suggests diffusion control. In a static test, the concentration of species in the leachate increases with time and the leach rate reduces gradually because of the reduction of the chemical affinity for dissolution. As dissolved species accumulate, the dissolution rate may also be affected by the solubility of secondary phase precipitates especially for incongruent dissolution. Based on a traditional transition-state-theory (TST) assuming elementary reactions with an adsorbed surface complex, ${ }^{97,98}$ an empirical exponential relationship (Fig. 2a) is assumed between overall dissolution rate with the Gibbs free energy of the dissolution reaction, $\Delta G_{r}$, the Gibbs free energy difference between bulk solids and dissolved molecules. This general behavior is observed for dissolution of silicates (e.g., albite, feldspar, and anorthite). ${ }^{99-101}$ $\Delta G_{\mathrm{r}}$ quantifies the deviation from equilibrium and can be
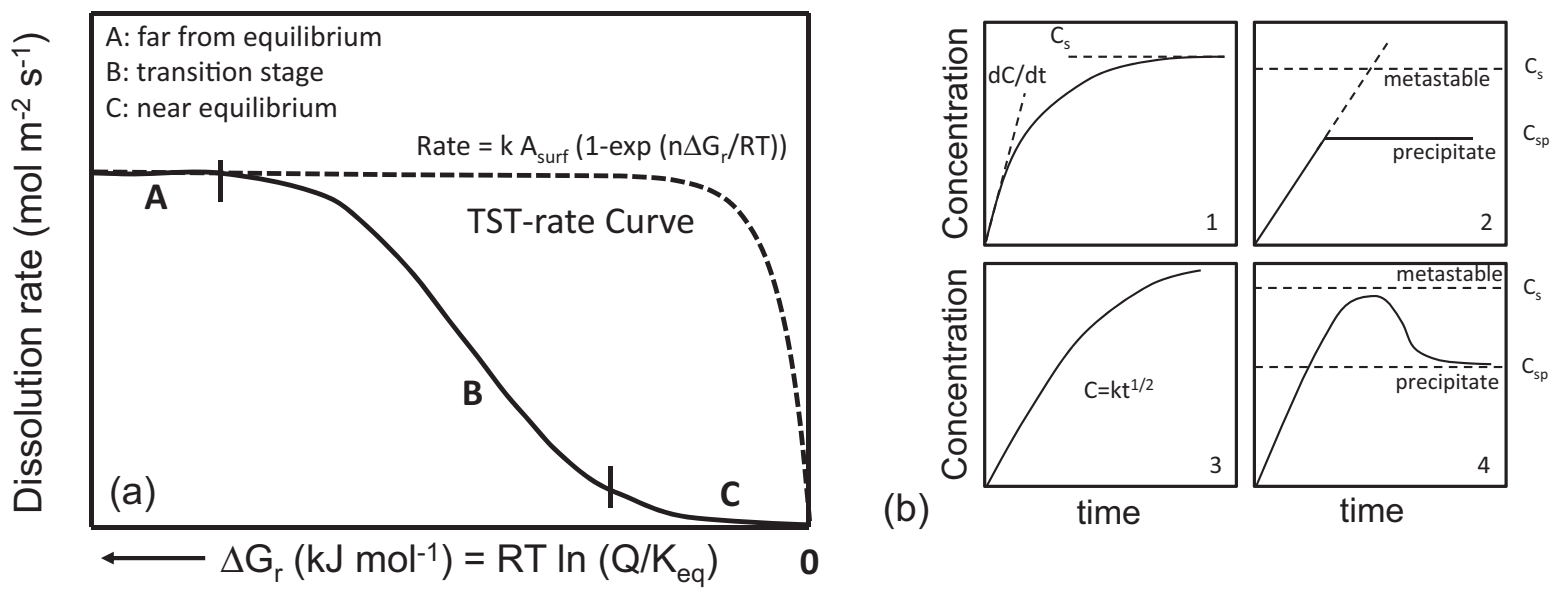

Fig. 2 Schematics of kinetics of crystal dissolution in water. a Dissolution rates as a function of the thermodynamic-driving force Gibbs free energy of the dissolution reaction, $\Delta G_{\mathrm{r}}$. A sigmoidal relationship can be characterized by three distinct regions: a dissolution plateau above a critical undersaturation for conditions far from equilibrium (stage A); a transition regime in which the dissolution rate is reduced substantially with less undersaturation (stage B); and a slow dissolution rate close to equilibrium (stage C). The transition-state theory rate is included for comparison, showing a significant deviation of the dissolution rate near equilibrium. $\mathbf{b}$ Phenomenological description of crystal dissolution kinetics in water. Solution concentration-time curves for different dissolution mechanisms: (1) transport controlled mechanism and saturation concentration approaching equilibrium; (2) linear kinetics far from equilibrium and truncated by saturation concentration with respect to a precipitate phase with rapid precipitation kinetics; (3) diffusion controlled kinetics showing a parabolic rate law with the formation of alteration layers; and (4) dissolution with precipitation of a product phase with a sluggish precipitation kinetics. $C$ is the concentration of dissolved species; $C_{\mathrm{s}}$ is the concentration of dissolved species under saturated conditions; $C_{\mathrm{sp}}$ is the concentration of dissolved species with respect to the secondary precipitate. (a adapted with permission from ref. ${ }^{95}$, copyright Elsevier 2006) (b adapted with permission from ref. ${ }^{96}$, copyright Elsevier 1992) 
estimated based on the ion activity product of the dissolution reaction, $Q$, and the corresponding equilibrium constant $K_{\text {eq }}$. Like with glasses, such a thermodynamic equilibrium cannot be achieved for some crystalline structures that are thermodynamically unstable, and the dissolution reaction is spontaneous and irreversible in these cases. But for some other crystalline materials, such an equilibrium can be reached and dissolution can then stop. For crystal dissolution in a static experiment, the system typically starts from far from equilibrium conditions and thus the crystal dissolution rate can be treated as constant and independent of undersaturation (with larger negative $\Delta G_{r}$ ) (Stage A in Fig. 2a). The leachate concentration increases linearly with time for crystal dissolution with high solubility and far from equilibrium. With a build-up of the dissolved molecules in bulk solution and thus reduced undersaturation, the dissolution rate reduces accordingly and the leachate concentration in solution reaches saturation (see the concentration-time curve Fig. 2b-1).

The TST-based rate model provides a direct link between the bulk dissolution of crystals and the thermodynamic quantity $\Delta \mathrm{G}_{\mathrm{r}}$ of the dissolution reaction. However, it significantly overestimates the dissolution rate, particularly approaching equilibrium where the dissolution rate is low and displays an almost linear dependence on the Gibbs free energy (stage C). Following the dissolution plateau (stage A) for crystal dissolution starting far from equilibrium, a transition stage (stage $B$ ) occurs with rapidly reduced dissolution rate with reduced negative $\Delta G_{\mathrm{r}}$. Discrepancies in bulk dissolution and the TST-based rate model were observed for albite $\left(\mathrm{Na}\left(\mathrm{AlSi}_{3}\right) \mathrm{O}_{8}\right)$ feldspar ${ }^{95}$ and gibbsite $\left(\mathrm{Al}(\mathrm{OH})_{3}\right) .{ }^{102}$ Thus, the TST-based rate model developed for elementary reactions does not describe global crystal dissolution processes consisting of multiple parallel and serial reactions. Different rate expressions need to account for complex ceramic dissolution processes that underlie the rate disparity from the TST rate model. ${ }^{95,103}$

The three-dimensional crystal lattice structure, morphological/ surface defects and dissolution history have significant impacts on the dissolution rates of crystals. ${ }^{104}$ The dissolution starts at steps on the crystal surface, and flat-bottomed etch pits (etched pits on dissolved surfaces of single crystals) can be created from point defects and edge dislocations. The dissolution rate increases slowly with the deviation from equilibrium (i.e., $\Delta G_{r}=0$ ) at stage $C$. The rapidly increased dissolution rate in stage $B$ as compared with stage $C$ can be attributed to etch pits opening from screw dislocations above a critical Gibbs free energy. A step wave model was also proposed in which the etch pits are the major sources of steps producing massive dissolution, and a correlation between the step wave velocity, dissolution rate, and Gibbs free energy was established. ${ }^{105}$ The growth of etch pits propagating along the crystal surface increases the bulk dissolution rate to a constant value that displays a weaker dependency on the etch pit density at stage $A$.

A strong dependence of dissolution rate on crystal size has been documented in various experimental studies showing that the increased dissolution rate of smaller particles can be driven by the increased interfacial area. ${ }^{106,107}$ As the dissolution process is critically dependent on surface defects, e.g., steps and kink atoms, a coupling between the formation of kink and step sites significantly influences the detachment rate from crystal surfaces. A non-linear correlation was derived for the surface area normalized dissolution rate with decreased crystal size. ${ }^{108}$ For larger crystals, the deviation of dissolution rate from classical transport rate theory is gradually reduced. Grain boundaries may also impact the global dissolution rate of polycrystalline materials significantly, in which bond breaking or detachment may occur easily as a result of weaker or defective chemical bonds in grain boundary regimes. Grain boundaries may also be enriched with highly soluble elements or formed as intergranular glassy phases, ${ }^{109,110}$ thus leading to rapid initial dissolution rate during aqueous dissolution. ${ }^{111}$
The bulk dissolution kinetics are significantly impacted by precipitation or new phase formation for crystals that do not exist in equilibrium with aqueous solutions at ambient temperature and pressure. The concentration-time curve is controlled by the precipitation of low solubility phase(s) (Fig. 2b-2) if the precipitation kinetics are fast relative to the dissolution kinetics of the primary phase. Parabolic behavior is observed for ceramic phases with the formation of an alteration layer that behaves as a barrier on the surface, analogous to the surface alteration of glass, and the dissolution rate is under diffusion control (Fig. 2b-3). The concentration-time curve (Fig. 2b-4) can be modified with the formation of new precipitation phase(s) if the ions in solution exceed their solubility but with slow precipitation kinetics, e.g., in the case of silicate and aluminate reaction products.

Formation of alteration layer and dissolution-reprecipitation For many aluminosilicates with complex chemical bonding and composition, the relative rate of breaking of the metal-oxygen bonds decreases dramatically in the order monovalent $\left(\mathrm{Na}^{+}, \mathrm{K}^{+}\right.$ $\left.\mathrm{Cs}^{+}\right)>$divalent $\left(\mathrm{Ca}^{2+}, \mathrm{Mg}^{2+}, \mathrm{Sr}^{2+}, \mathrm{Ni}^{2+}\right)>$ trivalent $\left(\mathrm{Al}^{3+}, \mathrm{Fe}^{3+}, \mathrm{Cr}^{3}\right.$ $\left.{ }^{+}, \mathrm{B}^{3+}\right)>$ tetravalent $\left(\mathrm{Si}^{4+}, \mathrm{Ti}^{4+}, \mathrm{Zr}^{4+}\right)$ ions. ${ }^{92,112}$ Therefore, the dissolution of multi-oxide aluminosilicates proceeds by sequential breaking of the metal-oxygen bonds in that order, resulting in non-stoichiometric dissolution of these materials and formation of an alteration layer depleted in monovalent and divalent cations and enriched in high valence metal cations. ${ }^{112}$ If the dissolved metal cations are not essential to maintaining the material structure, as in clays and zeolites, the crystal structure may be stable. Otherwise, the structure could collapse or undergo transformation. Kinetics of the transformation can be addressed using either experimental or computational methods based on the Arrhenius and Avrami equations. Thermodynamically, if the barrier to the nucleation and crystal growth of the residual material with respect to thermal energy is low, a secondary crystalline phase may form. If not, an amorphous phase may form. Such an amorphous phase is complex, often gel-like with large pores enriched with water species, and can be thermodynamically metastable. The silicate network of the amorphous layer may undergo re-polymerization similar to the layers formed on dissolving silicate glasses. ${ }^{109,113,114}$

The structure and composition of ceramics can have a large impact on the rate and extent of the incongruent release of elements, and the formation and thickness of the leached alteration layers. In terms of structure, the dissolution rate for silicate-based crystalline phases decreases with increase of the connectedness of the $\mathrm{SiO}_{4}{ }^{4-}$ tetrahedral units and the number of bridging oxygens in the crystal structure. ${ }^{89,115}$ In terms of composition, the dissolution rate of Ca-olivine $\left(\mathrm{Ca}_{2} \mathrm{SiO}_{4}\right)$ is over 3 orders of magnitude higher than forsterite $\left(\mathrm{Mg}_{2} \mathrm{SiO}_{4}\right)$ over a range of $\mathrm{pH}$ values because $\mathrm{Mg}-\mathrm{O}$ bonds are stronger than $\mathrm{Ca}-\mathrm{O}$ bonds. ${ }^{89}$ For the formation of the leached layers, the thickness is largely controlled by the relative rate of the fast dissolving metal cations with respect to the slowest dissolving species, and if a steady state can be reached. For many silicates, such as olivine, pyroxenes, feldspars, and talc under acidic conditions, initial incongruent dissolution leads to a thin leached layer and dissolution may reach a steady state. The dissolution then can become congruent, resulting in the alteration layer dynamically maintaining a constant thickness while the material dissolves. ${ }^{116-}$ ${ }^{118}$ For titanates, including pyrochlore, perovskite and hollandite, incongruent dissolution often occurs with the formation of a titanate-enriched alteration layer. ${ }^{119-121}$ For wollastonite $\left(\mathrm{CaSiO}_{3}\right)$, however, a steady state can never be reached and $\mathrm{Ca}^{2+}$ in wollastonite crystals can be completely leached, resulting in an amorphous silica alteration product. ${ }^{118}$ Once $\mathrm{Ca}^{2+}$ is leached, the infinite chain of $\mathrm{SiO}_{4}$ units in wollastonite undergoes structural transformation and re-polymerization from $\mathrm{Q}^{2}$ to $\mathrm{Q}^{3}$ and $\mathrm{Q}^{4}$ units 
dominating in the alteration product, ${ }^{118}$ where $\mathrm{Q}^{n} \quad(n=1-4)$ reflects the connectivity of the $\mathrm{SiO}_{4}$ unit in silicate and $n$ represents the number of $\mathrm{SiO}_{4}$ units connected through the oxygen to a single silicon atom.

In general, the formation mechanisms and passivation properties of leached alteration layers on ceramics are not well understood, although incongruent dissolution, alteration layer formation, and surface precipitates have been documented. ${ }^{122}$ Two main mechanisms to explain the formation of the alteration layer on silicate minerals have been proposed and are currently under debate: dissolution-precipitation and ion exchange. ${ }^{28,33,37,123}$ It is worth noting that these mechanisms are also under discussion for silicate glass alteration. Based on experimental and theoretical studies, it is likely that both mechanisms are possible for both silicate glass and ceramics, depending on a number of variables, including ceramic composition and structure, $\mathrm{pH}$, temperature, and solution chemistry. Recent developments using atomic scale microscopy have revealed a coupled dissolution-precipitation mechanism. ${ }^{124}$ The alteration layers are formed in a tight interface-coupled two-step process: stoichiometric dissolution of the pristine crystals followed by subsequent precipitation of a secondary phase from a supersaturated boundary layer even though the bulk solution is undersaturated with respect to the secondary phases due to limited transport of reactive species from the boundary layer to the solution. However, the coupled dissolution-precipitation model is contradicted by the concept of preferential leaching of cations for the formation of alteration layers, which is postulated by most currently accepted models of incongruent dissolution. In addition to the two mechanisms described above, a replacement reaction may play a role in alteration layer formation. Understanding the formation mechanism is critical to the understanding of the physical and chemical properties of the alteration layer, which control the long-term dissolution rate of the materials and their performance in the environment.

Transformation of the alteration layer has a significant effect on the dissolution rate. Similar to metal and glass corrosion, alteration layers formed in ceramics may be thermodynamically metastable. They can experience amorphous-to-crystalline transitions, crystalline-to-crystalline transitions, as well as microstructure evolution and micro-chemical variation. These transformations are thermodynamics-driven and kinetics-controlled processes. For example, a 10-nm-thick $\mathrm{Ti}(\mathrm{OH})_{n}$ amorphous layer forms upon the hydrolysis reaction of $\mathrm{CaTiO}_{3}$ perovskite at room temperature (RT). ${ }^{125}$ At the high temperature of $150^{\circ} \mathrm{C}$, a $400 \mathrm{~nm}$ thick anatase $\mathrm{TiO}_{2}$ layer with a columnar grain structure forms on the surface of perovskite. ${ }^{126}$ The anatase alteration phase may react with $\mathrm{Fe}^{2+}$ in the near-field environment, leading to the formation of ilmenite $\mathrm{FeTiO}_{3}$, the final alteration product associated with the breakdown of the anatase film. ${ }^{127}$ Similarly, crystallization of the amorphous alteration layer of crystalline aluminosilicates phases is commonly observed. For instance, the alteration layer of naturally weathered potassium feldspars (after $\sim 15,000$ years) consists of a thin amorphous layer overlain by a variably thick (up to 1-2 $\mu \mathrm{m}$ ) overcoating composed of a silica-rich, amorphous matrix enriched in crystalline phyllosilicates. ${ }^{28,33,37,123}$ The alteration layer may also experience morphological instability upon drying and dehydration, e.g., in feldspar, leading to cracks and delamination from the crystal surface. ${ }^{128}$ The spallation of the alteration layer from the underlying material may be important for the weathering of minerals exposed to wet and dry cycles. It is not clearly described in the literature of ceramics dissolution whether or not an accelerated stage III corrosion similar to that found on glass occurs in ceramics upon the breakdown of the alteration layer. However, formation of secondary phases and transformation of the phases similar to the stage III process in glass corrosion do occur in the dissolution of ceramics. A systematic investigation is required to understand the fate of the passivation film and how the phase transformation, mechanical and chemical instability impact ceramic dissolution kinetics and mechanisms.

Effect of environmental parameters on the alteration layer

Environmental variables such as $\mathrm{pH}$, temperature, and solution composition have significant effects on the leached alteration layer formation. The alteration layer is often a result of the subtle balance of the kinetics of multiple processes involving different metal cations and activated complexes of different reactions. In terms of the effect of solution composition, as discussed above, the presence of dissolved metal cations in solution, often in equilibrium with surface metal cation complexes, increases the activities and chemical potentials of the dissolved species in solution, decreases the chemical affinity of the dissolution reaction, and thus inhibits elemental dissolution. For instance, the dissolution rate of aluminosilicates decreases with increasing concentration of dissolved alumina or silica species in solution. ${ }^{89,92}$ Thermodynamically, the enthalpy of the $\mathrm{H}^{+} \rightarrow \mathrm{Al}^{3+}$ exchange reaction at the surface of feldspar is estimated to be negative (about $-100 \mathrm{~kJ} \mathrm{~mol}^{-1}$ ), ${ }^{129}$ implying that the stability and thickness of the leached layer decreases with increasing temperature, given that the enthalpy of dissolution of amorphous silica is relatively small $\left(\sim 16 \mathrm{~kJ} \mathrm{~mol}^{-1}\right),{ }^{130}$ which is consistent with experimental results for albite leached layers. ${ }^{131}$ Because the activation energy is often lower for ion exchange reactions than for breaking of $\mathrm{Al}-\mathrm{O}$ and $\mathrm{Si}-\mathrm{O}$ bonds, a temperature increase may decrease incongruent dissolution, resulting in a decreased leached layer thickness. In terms of solution $\mathrm{pH}$, the effect on ceramic and mineral dissolution rates is through the change of $\mathrm{H}^{+}$activity in solution and surface activated complexes, and the latter often change the dissolution mechanism. For metal silicates, the dissolution rate decreases continuously with increasing $\mathrm{pH}$ in the acidic region and then becomes $\mathrm{pH}$ independent under basic conditions. $^{89,92}$ For titanate-based hollandite, the dissolution rate decreases continuously with increasing $\mathrm{pH}$, accompanied by the reduction of alteration layer thickness. ${ }^{121}$ For metal aluminosilicates, a minimum dissolution rate is usually observed around neutral $\mathrm{pH}$ and the rate increases as the solution becomes either more basic or more acidic. ${ }^{89,92}$ The change of mechanism with $\mathrm{pH}$ significantly affects the formation of the leached alteration layer. For instance, at $\mathrm{pH}<4.8$, wollastonite dissolves incongruently to form a thick leached layer, which may continue until complete transformation to Ca-free alteration product. At $\mathrm{pH}>4.8$, congruent dissolution occurs quickly after an initial period without the formation of an observable leached alteration layer. ${ }^{118} \mathrm{~A}$ rapid release of $\mathrm{Cs}$ and $\mathrm{Ba}$ occurs in titanate-based hollandite at low $\mathrm{pH}$ values and the dissolution becomes more incongruent at high $\mathrm{pH}$ values. $^{119}$

Redox reaction-enhanced dissolution of ceramics and minerals In natural systems, many elements can undergo extensive redox cycles. The major redox couples are $\mathrm{O}_{2} / \mathrm{H}_{2} \mathrm{O}$ due to the abundance and reactivity of $\mathrm{O}_{2}, \mathrm{MnO}_{2} / \mathrm{Mn}^{2+}, \mathrm{Fe}(\mathrm{OH})_{3} / \mathrm{Fe}^{2+}$ under sub-oxic conditions and $\mathrm{SO}_{4}{ }^{2-} / \mathrm{H}_{2} \mathrm{~S}$ or $\mathrm{SO}_{4}{ }^{2-} / \mathrm{HS}^{-}$under anoxic conditions. ${ }^{132}$ For ceramics and minerals containing variable valency elements such as transition metals (e.g., $\mathrm{Cr}, \mathrm{Mn}, \mathrm{Fe}, \mathrm{Cu}, \mathrm{Tc}$ ), actinides (e.g., U, Pu), and $\mathrm{S}, \mathrm{As}$, and $\mathrm{Se}$, dissolution and precipitation of solid phases typically accompanies the change of oxidation state, which in turn impacts material solubility and dissolution rate. $\mathrm{Fe}(\mathrm{III})$ and $\mathrm{Mn}$ (III, IV) oxides are subject to reductive dissolution, and $\mathrm{Fe}(\mathrm{II})$ silicates, sulfides, $\mathrm{TcO}_{2}$, and U(IV) oxides to oxidative dissolution. ${ }^{133}$ For example, $\mathrm{U}(\mathrm{IV})$ in $\mathrm{UO}_{2}$ can be readily oxidized to $\mathrm{U}(\mathrm{V})$ and $\mathrm{U}(\mathrm{VI})$, forming successive surface films in aqueous solution or uranyl carbonate or phosphate phases in solutions containing carbonate or phosphate. ${ }^{134,135}$ Uranium in nuclear glass can also undergo redox reactions depending on the redox potential of the environment. ${ }^{136}$ For Fe(III) and Mn(III,IV) 
oxides, reduced metal ions can be more easily detached from the surfaces than non-reduced metal-oxygen bonds. A surface complex model was derived for surface controlled reductive and oxidative dissolution considering surface coordination combined with an electric double layer theory. ${ }^{137}$ Specifically, functional groups present at the surface of ceramics and minerals (e.g., $-\mathrm{OH}$ on oxides and silicates, $-\mathrm{SH}$ on sulfides and $-\mathrm{CO}_{2} \mathrm{OH}$ on carbonates) can react with $\mathrm{H}^{+}, \mathrm{OH}^{-}$, metal ions and ligands, oxidants and reductants, forming surface complexes and transferring electrons with the surface metal ions. The dissolution rate is found to be proportional to the concentration of the surfacebound reductants and oxidants. Redox reaction enhances dissolution of some ceramics and minerals, thus it significantly influences chemical weathering and hydrogeochemical performance. Redox reaction-enhanced dissolution is also observed in titanate-based ceramic waste forms, e.g., hollandite, in which $\mathrm{Ti}^{3+}$ is used to charge-compensate monovalent $\mathrm{Cs}^{+}$. A linear correlation was identified for the release of $\mathrm{Cs}^{+}$upon oxidation of $\mathrm{Ti}^{3+}$ in the structure by an oxidizing acid, forming a titanate-enriched surface layer (rutile and brookite). ${ }^{120}$ For nuclear waste management, when redox active and semi-conductive waste forms such as hollandite or $\mathrm{UO}_{2}$ are enclosed in a stainless canister, redox reaction-enhanced dissolution is further coupled with the canister corrosion and radiolysis in which strong oxidants such as aqueous $\mathrm{Fe}^{3+}$ species, hydrous iron oxides and $\mathrm{NO}^{3-}$ can be present. ${ }^{138}$

\section{Challenges in understanding the leached alteration layer}

The leached alteration layer has long been observed in experiments and explained by theory. However, the properties of the alteration layer and their effects on long-term dissolution rate are not fully understood. It is notable that the leached layer formed under incongruent dissolution conditions is usually protective and has a passivation effect on dissolution. However, how the leached layer decreases the dissolution rate over time is not well understood. This requires the physical properties of the layer to be well characterized. There is also a need to distinguish between the observations of dissolution far from and close to the equilibrium conditions. Similar to silicate glasses, dissolution of ceramics and minerals, formation of leached layers and secondary phases, and solution chemistry are intimately coupled and this coupling evolves with time. The origin of the leached layer formation is still a matter of debate including whether the ion exchange or dissolution-precipitation mechanism dominates the formation. This is significant because different reaction mechanisms could lead to dramatically different predictions of long-term dissolution rates. In addition, replacement reactions may also play a role in leached layer formation. The dissolution mechanisms of many ceramics with varied valence elements are complex, redox sensitive, and often surface catalyzed in aqueous environments. The electron transfer reactions often involve many elementary steps, passivating film and secondary phase formation, coupled with the electrolyte and water species in solution. To make things even more complicated, microbes in the environment can play a role as can radiolysis for disposed nuclear waste. As such, although phenomenological descriptions of the dissolution of crystalline ceramics are well documented in the literature, each of the elementary steps must be addressed before the complete system can be understood in full detail.

\section{OVERVIEW OF METALLIC CORROSION}

There is a strong thermodynamic-driving force for most metals to corrode when exposed to an aqueous environment. Considerable energy is required to convert mined ores into metals and alloys, and that energy is the driving force for the reaction of the reduced metal back to an oxidized form similar to an ore. ${ }^{139}$ Metallic corrosion is an electrochemical process involving the oxidation of metal, which releases electrons, and the consumption of those electrons by a simultaneous reduction process such as oxygen reduction or hydrogen evolution.

Most metals and their alloys are susceptible to corrosion and must be protected by the use of coatings to separate them from the environment, inhibiting chemicals to change the environment, or cathodic protection to reduce the thermodynamic-driving force. However, some metals and alloys are corrosion resistant because of the spontaneous formation of a thin protective surface film, called a passive film. The prime examples of such alloys are $\mathrm{Fe}-\mathrm{Cr}$ (stainless steels) and $\mathrm{Ni}-\mathrm{Cr}$ alloys that form a $\mathrm{Cr}$ oxide passive film, but $\mathrm{Al}, \mathrm{Ti}, \mathrm{Ta}, \mathrm{Ni}, \mathrm{Cu}$, and their alloys can also be spontaneously passive because of the formation of a passive film composed of their respective oxides or hydroxides. One or more oxide may form based on the alloying elements or a new oxide may form such as a spinel. The rest of this section on metal corrosion will focus on such corrosion-resistant alloys (CRAs), including the formation of passive films and the localized breakdown of those films and the resultant accelerated corrosion.

Protective oxide formation

As is true for glasses and ceramics, passivation of metals is achieved when the corrosion rate is very low due to the presence of a thin and dense film under conditions where a high corrosion rate is expected in the absence of a passive layer. ${ }^{140}$ Passivation initiates upon adsorption of species such as $\mathrm{O}$ and proceeds with the formation of passivating films consisting of metal oxides, hydroxides, carbonates, phosphates, or other species depending upon their thermodynamic stability as a function of the prevailing conditions. ${ }^{141}$ However, passive films can deviate from predictions of thermodynamics of bulk materials because of metastability, pseudomorphic or polymorphic effects, and solute trapping. ${ }^{139}$ The focus here will be on oxide passive films.

The kinetics associated with passivation and decrease of corrosion rate on metals and alloys depend on a variety of factors including the relative kinetics of oxide formation, cation ejection, and chemical dissolution, the types of point defects in the oxide and their ionic and electronic transport characteristics in response to the electric field imposed across the oxide, as well as metal -film and film-solution interfacial reaction fluxes. ${ }^{142,143}$ A number of environmental factors such as temperature, $\mathrm{pH}$ and electrolyte composition are also important. ${ }^{139,141}$

Protective oxides may be only nanometers in thickness and electronically semi-conducting such as for $\mathrm{Fe}, \mathrm{Ni}$, and $\mathrm{Cr}$, or thicker and insulating such as on $\mathrm{Al}, \mathrm{Ta}$, and $\mathrm{Zr} .{ }^{144,145} \mathrm{Cr}$, Ni, and Fe form oxides that are often in a multi-layered structure ${ }^{139,141}$ with inner barrier oxides covered by an outer hydroxide layer such as in the case of $\mathrm{Cr}(\mathrm{OH})_{3}{ }^{-} 0.3 \mathrm{H}_{2} \mathrm{O} .^{146}$ The outer layer may be highly porous, gel-like, or both and facilitate electrolyte exchange. In the case of alloying, a layered or laterally heterogeneous phase separated oxide may form, a spinel may form comprised of various alloying elements, or a certain oxide may form preferentially due to thermodynamic or kinetic factors. ${ }^{147}$ Selected alloying elements may be preferentially enriched in the oxide. A critical alloying content in the bulk alloy required for sufficient enrichment to form a protective oxide is often cited, although theories for the critical threshold differ. ${ }^{148,149}$ While the passive film on $\mathrm{Al}$ is amorphous, most passive oxide films are crystalline with disordered regions between oxide crystals and an epitaxial relationship of crystalline regions with the underlying metal. Passive films often become more crystalline over time. Therefore, details of the passivation nucleation and growth processes vary with surface orientation and morphology. Moreover, oxides contain grain and/or phase boundaries that may have different structure, composition and electronic properties. ${ }^{150,151}$

Prominent growth models predict logarithmic, inverse logarithmic, or parabolic growth depending on the details. ${ }^{143,152-156}$ The 


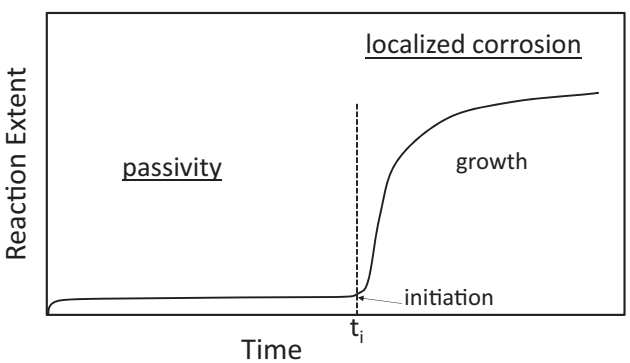

Fig. 3 Schematic of reaction rate vs. time for a CRA showing initial high rate of reaction followed by rapid slowing as passive film forms and thickens. In benign environments, the passivated alloy can achieve a steady state condition with very low residual rate of reaction. However, in the presence of corrosive species such as halides, an incubation period of passivity, $t_{\mathrm{i}}$, can be followed by local breakdown of the passive film and the onset of localized corrosion, leading to a rapid increase in reaction rate at local sites. The rate of growth of localized corrosion often grows as $t^{n}$ with $n$ between 0.5 and 0.33

first two represent the behavior of CRAs under most conditions and both describe fast kinetics during the initial stages of passivity followed by rapid slowing as the oxide thickens. Therefore, the kinetics are similar in form to what was described for glasses and ceramics, as represented schematically in Fig. 3.

The mechanism of oxide formation and growth includes both ionic and electronic transport through the oxide. ${ }^{142}$ Metal cation transport usually dominates over that of anions, ${ }^{157}$ whereas electronic transport may be dominated by either electrons or holes. Environmental conditions such as $\mathrm{pH}$ and applied potential, as well as material characteristics such as metal orientation, epitaxy, and misfit at the oxide/film interface, oxide structure, oxide composition and ionic defect concentrations, control the interface reactions and ion transport through the oxide and its growth. ${ }^{143}$ In various growth models, cation ejection, dissolution, or field-assisted transport dominates the overall growth process. Rarely is mass transport through the bulk solution phase ratecontrolling for thin film passivity, but it can be an important factor in thick film passivation. For thin films of nm thickness, a high electric field assists the diffusion of ionic point defects necessary for oxidation reactions. ${ }^{158}$ One hypothesis is that film growth is dependent on the migration of interstitial cation vacancies from the film/solution interface to the metal/film interface where the rate-limiting step is cation injection. The uniform electric field produces a shift in the Fermi level across the film, also called the Mott potential, which drives ionic transport and electron tunneling. ${ }^{159}$ Cabrera and Mott's solution for thin film growth at low temperatures yields an inverse logarithmic oxide growth model in which the inverse of the film thickness varies with -In (t). ${ }^{152}$ This model can be extended to films thicker than several nanometers by assuming that electron transport occurs via thermionic emission or by typical semiconductor processes across an oxide, yielding parabolic growth kinetics as seen by Wagner. ${ }^{159}$

\section{Passive film breakdown}

Under sufficiently aggressive conditions, the protectiveness of the thin passive film on a metal surface will breakdown locally, resulting in accelerated dissolution in those local sites and the formation of pits or crevices. The rate of dissolution within these sites decreases with time as the site grows, but the initial rate can be 6-8 orders of magnitude larger than the steady state dissolution rate of the passivated surface. ${ }^{160}$

Models of passive film breakdown must account for the local nature of the attack, which is easily explained when discrete microstructural oxide or substrate defects are present that provide physical, chemical, structural, or electronic non-uniformities.
Susceptible alloys often contain a high density of microstructural defects and second phase particles, often with local weak passivating films that are sensitive to breakdown. For stainless steels, the initiation sites are usually inclusions, particularly MnS inclusions, as the $S$ in these particles spoils passivity. ${ }^{139}$ Other initiation sites include other anodic particles or phases, regions near cathodic particles, and solute-depleted zones that can form near grain boundaries as the result of particle precipitation on the grain boundaries. These zones subsequently form weaker overlying oxides as in sensitized stainless steels, where the precipitation of $\mathrm{Cr}$ carbide particles at grain boundaries leaves the nearby matrix $\mathrm{Cr}$ concentration below the critical value required to form a $\mathrm{Cr}$ (III) rich passive film. Highly CRAs contain homogeneous oxide films and local breakdown may be attributed to defects in the oxide, such as grain boundaries and triple points, which facilitate electrolyte interaction and lower activation energies. ${ }^{161}$ Proposed breakdown mechanisms on these films are uncertain because some details of the steps lack experimental verification, robust theoretical bases, or both. A universal model for oxide breakdown is lacking. The dependence on halide ion concentration, incubation times, potential driving forces, and the precise conditions that cause instability and/or film breakdown must be considered.

At least three prominent theories are posited for breakdown of passive oxide films on CRAs including local thinning, voiding and collapse, as well as stress-induced rupture. ${ }^{162}$ Adsorption of chloride at specific sites based on some heterogeneity can trigger breakdown as the first of several steps in the process. Passive film breakdown is often interface-controlled or controlled by processes within the oxide. Oxide thinning is based on release of loosely bound metal cations in the passive film, which is encouraged by $\mathrm{Cl}^{-}$adsorption in competition with $\mathrm{OH}^{-} \cdot{ }^{162} \mathrm{M}^{\mathrm{Z}+}-\mathrm{Cl}^{-}$or $\mathrm{M}^{\mathrm{Z}}$ ${ }^{+}-\mathrm{OH}^{-}-\mathrm{Cl}^{-}$surface complexes can form more soluble molecular species than $\mathrm{M}-\mathrm{O} .^{139,161,162}$ By this process, the $\mathrm{M}-\mathrm{O}$ barrier film thickness is reduced locally ${ }^{163-167}$ and may not be compensated by additional oxide formation. Enhanced local passive film dissolution at grain boundaries with fewer bonds and lower activation energies may account for site specificity. ${ }^{162}$ Ramifications include a higher electric field across a thinner remaining oxide, which triggers additional $\mathrm{M}$ oxidation. The cation vacancy defect densities in the oxide may be increased simultaneously via replacement of oxygen anions with halide anions. ${ }^{162}$

Cation vacancy formation and voiding can take place in a variety of ways. For instance, ion transport in the barrier film layer usually occurs via anion and cation vacancies. If transport is dominated by metal cations, faster cation transport followed by dissolution $\left(\mathrm{M}^{\mathrm{z}+}\right.$ release) at the metal/film interface (Eq. 1) will lead to formation of cation vacancies, $V_{M}{ }^{z-}$. 139,162

$\mathrm{M}_{\mathrm{M}} \rightarrow \mathrm{M}^{\mathrm{z}+}+\mathrm{V}_{\mathrm{M}}^{\mathrm{z}-}$

Injection of cation vacancies via this process may grow into vacancy clusters if transport rates are slow. Kirkendall voiding can also result from differential ionic transport rates. ${ }^{168-171}$ Either type of void introduces local stresses and structural instability, leading to local collapse of the film and depassivation.

Finally, various processes such as $\mathrm{Cl}^{-}$adsorption and absorption, electrostatic repulsion, preferential dissolution and change in lattice parameter, dielectric properties, epitaxial films, or large anion penetration can generate stresses that rupture the passive film. ${ }^{139,161,162} \mathrm{Cl}^{-}$penetration via oxygen vacancies is debated, but it is proposed that it can occur in highly defected regions, lowering surface energy and leading to cracking of the barrier layer and local breakdown. ${ }^{172-174}$ The oxide film may be in a state of continual breakdown and repair even without $\mathrm{Cl}^{-}$, but the breakdown occurs at a higher rate and the repair at a slower rate in the presence of $\mathrm{Cl}^{-} .{ }^{162}$ All of the processes described above require some time for interactions of the environment with the oxide to occur before the critical conditions for breakdown 
develop; thus an incubation time is usually observed before breakdown and local corrosion in many CRAs. ${ }^{175}$

\section{Stabilization and propagation of localized corrosion}

Stabilization of localized corrosion is a practical concern owing to perforation of structures or the development of local stress concentration at these sites, which can lead to cracking and failure in the presence of stresses. Localized corrosion in the form of pits or crevices is considered to be autocatalytic because the conditions that spontaneously form promote continued growth. ${ }^{176}$ The reactions within pits, considering divalent cation production via anodic oxidation of a generic metal $M$, are:

$\mathrm{M} \rightarrow \mathrm{M}^{2+}+2 \mathrm{e}^{-}$

$\mathrm{M}^{2+}+2 \mathrm{H}_{2} \mathrm{O} \rightarrow \mathrm{MOH}^{+}+\mathrm{H}^{+}+\mathrm{H}_{2} \mathrm{O} \rightarrow \mathrm{M}(\mathrm{OH})_{2}+2 \mathrm{H}^{+}$

The cathodic reaction outside of pits on the passive surface, considering a neutral aerated solution, is:

$\mathrm{O}_{2}+2 \mathrm{H}_{2} \mathrm{O}+4 \mathrm{e}^{-} \rightarrow 4 \mathrm{OH}^{-}$

The primary locations of the anodic and cathodic reactions become spatially separated with the cathodic reaction, i.e., oxygen reduction (Eq. 4), occurring at the outer passive surface and the anodic reaction, i.e., metal oxidation (Eq. 2), occurring within the pit or crevice. This leads to a gradient in solution composition because the cathodic reactions increase the $\mathrm{pH}$, and hydrolysis of metal ions result in a decrease in $\mathrm{pH}$ within the pit or crevice (Eq. 3). Electrons flow from the local anodes to cathodes, and the resulting potential gradient drives electromigration of cations toward the cathode and anions toward the anode. As pitting corrosion almost always occurs in chloride-containing environments, chloride ions are transported by migration up a concentration gradient to enrich in the local pit environment. Pit solutions therefore have high concentrations of $\mathrm{Cl}^{-}, \mathrm{H}^{+}$, and metal cations. This very aggressive environment inhibits the repassivation of pit walls and promotes continued pit growth.

There are many important factors in localized corrosion, including alloy composition and microstructure, surface roughness, or shielding to create a crevice, electrochemical potential, solution composition (importantly chloride concentration), and temperature. ${ }^{176}$ These factors will be addressed briefly in turn.

For localized corrosion to occur, the metallic alloy must be passive, which for Fe means that the alloy must contain sufficient $\mathrm{Cr}$ to form a protective passive film. The resistance to localized corrosion usually increases with $\mathrm{Cr}$ content as a passivating element. ${ }^{177}$ Other alloying elements improve passivity by different mechanisms, and while there is still a lack of agreement, it can be considered that Mo inhibits localized corrosion by solute vacancy interactions in the oxide ${ }^{178}$ and/or as ions after dissolving in the local environment, ${ }^{179} \mathrm{~W}$ tends to passivate in the acidic pit environment unlike most metals, ${ }^{180}$ and $\mathrm{N}$ dissolution into the pit environment counteracts the local acidity. ${ }^{181-183} A$ strong synergy is produced between certain alloying elements such as $\mathrm{Cr}$ and $\mathrm{Mo}$, the basis of which remains unclear. ${ }^{184}$

Pitting corrosion will initiate at the particular site on a boldly exposed surface that is most susceptible to attack. Examples of susceptible structures in stainless steels were given above. Crevice corrosion will occur at regions of shielding of the surface such as at pipe flanges, fastened lap joints, or under deposits. ${ }^{139}$ Crevice corrosion occurs under less aggressive conditions than pitting corrosion on a boldly exposed surface because the diffusion barrier associated with the crevice former makes it easier for concentrated local environments to form. Pitting corrosion on a boldly exposed surface occurs more readily and under less severe conditions on rough or abraded surfaces than on smoothly polished surfaces because the roughness creates small features like crevices.
The electrical potential, either the open circuit potential set by the combination of the anodic and cathodic reactions on the surface or the potential controlled by a potentiostat, has a dominant role in localized corrosion. ${ }^{176}$ Localized corrosion is enhanced and stabilized with increasing potential because it accelerates the rate of corrosion in the local site after breakdown. There exist critical potentials in localized corrosion that can be used to assess the susceptibility of the alloy in a given environment. Stable pits can form above the pitting potential, $E_{\text {pit, }}$ and they continue to grow at potentials above the repassivation potential, $E_{\mathrm{RP}}$. Alloys with high values of $E_{\mathrm{pit}}$ and $E_{\mathrm{RP}}$ tend to have higher resistance to pitting corrosion. It should be noted that pits do form at potentials below $E_{\text {pit, }}$ grow for a period often on the order of seconds, and then repassivate. These metastable pits can also form above $E_{\mathrm{pit}}$ in the induction period before the initiation of a stable pit. ${ }^{185}$

The concentration of species in the aqueous environment has a large effect on the tendency for localized corrosion. ${ }^{177}$ Important factors include $\mathrm{pH}$, anions such as halide, and chelating or complexing species, which can alter the thermodynamics and kinetics. Localized attack is promoted by the presence of an aggressive species in the environment, which is almost always chloride. The tendency for localized corrosion increases as the chloride ion concentration increases, but decreases when inhibiting species are added to the environment.

Finally, temperature plays a critical role in localized corrosion, which will only occur above the critical pitting temperature (CPT) for that alloy. ${ }^{182,186-189}$ CPT exhibits much smaller statistical distributions than $E_{\mathrm{pit}}$ for CRAs, and so is also used as a measure of resistance to pitting. The CPT has been explained by the different temperature dependencies for salt film and passive film formation so the CPT is the temperature above which a metal salt film will form on the pit wall instead of a passive film.

The growth rates of stable pits and crevices can be controlled by mass transport, interface, or ohmic effects. Pits growing under mass transport control are often polished, whereas grain orientation effects are seen when pitting is interface controlled since interfacial thermodynamic and kinetics are often strongly dependent on crystal structure. Ohmic effects originate from the spatial separation of the anodic reaction within the localized corrosion site and the cathodic reaction on the outer surface passive film. Various controlling factors mentioned above such as mass transport, ohmic or charge transfer control give rise to a pit penetration depth that is a specific function of exposure duration such as time raised to the $1 / 2$ or $1 / 3$ power depending on the governing details. ${ }^{190-192}$ This is shown qualitatively in Fig. 3 where the extent of damage increases rapidly with time once localized corrosion sites form.

Pits can also transition into other modes of corrosion such as corrosion fatigue, intergranular corrosion, and stress corrosion cracking. ${ }^{193}$ The criteria for these transitions involves a combination of chemical, electrochemical, microstructural, and mechanical factors that are beyond the scope of this review.

The relative importance of passive film properties and pit dissolution kinetics in controlling the pitting corrosion process has been a matter of debate for some time. Pits cannot initiate unless the passive film breaks down, so the properties of the passive film and its ability to resist breakdown is clearly of importance. However, breakdown of passive films followed immediately by repassivation is not of practical concern, so it can be considered that the most critical aspect of pitting corrosion is the stabilization of the localized attack. A recent paper described how both perspectives are of importance, with pit stabilization controlling under aggressive conditions where breakdown is frequent and passive film breakdown dominating under less aggressive conditions (or in a more resistant alloy). ${ }^{194}$ 


\section{SILICATE GLASS, CRYSTALLINE CERAMIC, AND METAL CORROSION: SIMILARITIES AND DIFFERENCES}

In this section, the mechanisms of corrosion of the three material classes will be compared and contrasted, highlighting similarities and differences. The goal is to provide guidance for future interdisciplinary synergistic activities that could lead to advances in understanding.

\section{Surface films form on all three materials}

Surface films can control the dissolution rate of all three materials. When the surface films are protective, they act by separating the unaltered substrate from the environment. The extent of protection depends largely on the properties of the surface film, e.g., its thickness, conductivity, diffusivity, and porosity. In aqueous environments, glass, ceramics, and metals form insulating or semiconducting passive oxide films that have some similarity to each other. Because the localized corrosion of a passive metal requires the breakdown of the passive film, the processes may be related to the mechanisms of degradation of ceramics and glass. The passive film/alteration layer on metals and ceramics can be either amorphous or crystalline, although the passive films on metallic CRAs are usually crystalline. The passive layer formed on silicate glass is amorphous. The formation of crystalline products on glass are usually not protective and may even grow at the expense of the amorphous passivating layer. Formation of surface films on all the materials may decrease the corrosion rate but cannot stop it because, thermodynamically, the corrosion is a spontaneous and irreversible process driven by thermodynamics. For some crystalline materials, the thermodynamic driving force can diminish and even reverse, resulting in growth of the material by deposition. In contrast, glass and metals generally cannot spontaneously deposit from aqueous solution.

Cross-sectional images of example surface films formed on corroded samples taken from the literature are shown in Figs. 4-6. Figure 4 shows a TEM cross section of the passive film formed on Fe-20Cr-10Ni in deaerated, $50^{\circ} \mathrm{C}$, pH 8.5 borate buffer solution at 0.4 VSCE for $12 \mathrm{~h}^{195}$ The film is seen to be about $2.5 \mathrm{~nm}$ thick. Fast Fourier transform images indicate that the passive film is amorphous. Electron energy loss spectroscopy indicated that the passive film was enriched in $\mathrm{Cr}$, contained $\mathrm{Fe}$, and was practically devoid of $\mathrm{Ni}$.

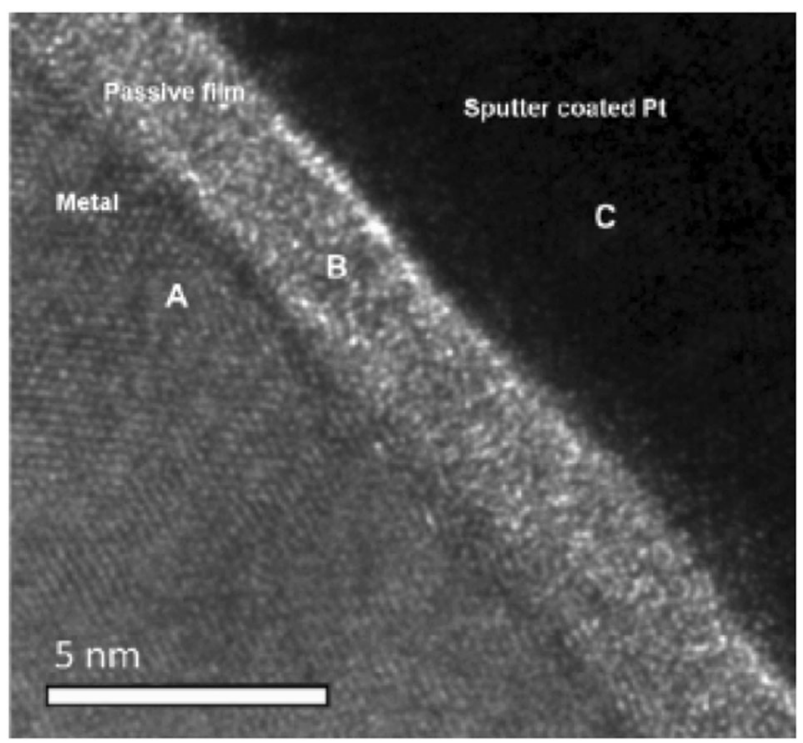

Fig. 4 TEM cross section of the passive film on Fe-20Cr-10Ni formed in deaerated, $50^{\circ} \mathrm{C}, \mathrm{pH} 8.5$ borate buffer solution at 0.4 VSCE for $12 \mathrm{~h}$. (reproduced with permission from ref. ${ }^{195}$, copyright Elsevier 2014)
The alteration layer formed on ISG exposed for 209 days at $90^{\circ}$ $\mathrm{C}$, in $\mathrm{pH}$ 9, silica-saturated solution is shown in Fig. $5 .{ }^{35}$ This is an SEM image formed by fracturing the glass. The alteration layer is about $0.5 \mu \mathrm{m}$ thick, much thicker than that formed on the metal alloy. The glass was exposed for a much longer period than the metal, but the metal passive film is not expected to thicken appreciably with longer exposure after reaching a steady state. This layer is a nanoporous layer with high concentrations of $\mathrm{Si}, \mathrm{Al}$, $\mathrm{Ca}$, and $\mathrm{Zr}$ and depleted in $\mathrm{Na}$ and $\mathrm{B}$.

The reaction layer formed on $\mathrm{U}$-containing titanate pyrochlore $\left(\mathrm{Ca}\left(\mathrm{U}_{0.5} \mathrm{Ce}_{0.25} \mathrm{Hf}_{0.25}\right) \mathrm{Ti}_{2} \mathrm{O}_{7}\right)$ exposed for 835 days at $\mathrm{RT}$ in $\mathrm{pH} 4$ potassium acid phthalate buffer with $0.005 \mathrm{M} \mathrm{HCl}$ is shown in Fig. $6 .{ }^{196}$ The layer ranged from 6 to $10 \mathrm{~nm}$ in thickness, enriched in $\mathrm{Ti}$ and $\mathrm{Hf}$ and depleted in $\mathrm{Ca}$ and $\mathrm{U}$. It is generally believed that incongruent dissolution with preferential release of soluble elements leads to the formation of the alteration layer enriched with less-soluble elements, which were $\mathrm{Ti}$ and $\mathrm{Hf}$ in this case. The alteration film behaves as a passivation layer to prevent further release of elements and thus reduces the dissolution rate of ceramics. Such alteration layers are primarily amorphous, but may experience an amorphous-to-crystalline phase transformation, resulting in the formation of $\mathrm{nm}$-sized $\mathrm{TiO}_{2}$ crystals over long times. The enrichment of a protective surface layer with lesssoluble elements also occurs in metals and glasses. It should be noted that, whereas the surface film shown in Fig. 6 is quite thin, ceramics can under certain conditions also form a relatively thick alteration layer like the one shown in Fig. 5 for glass. ${ }^{119,125}$

There are similarities in the kinetics of attack

Glass exhibits three stages of corrosion. The initial rate of attack is fast, controlled by the hydrolysis of $\mathrm{Si}-\mathrm{O}-\mathrm{M}$ bonds $(\mathrm{M}=\mathrm{Si}, \mathrm{Al}$,

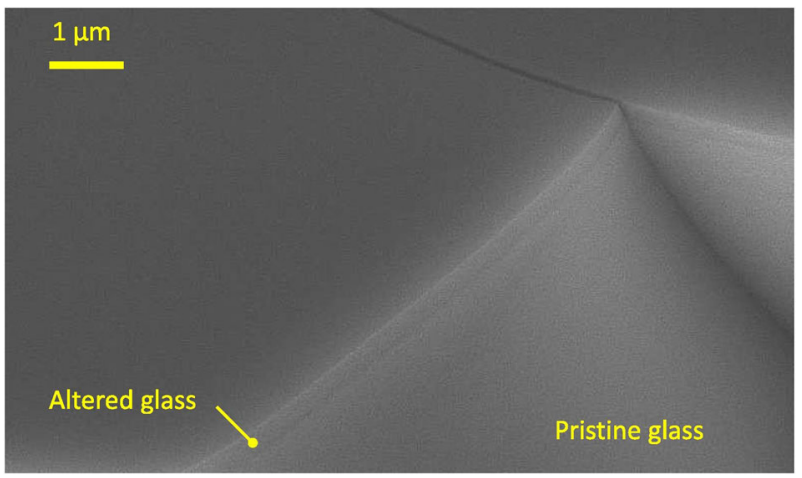

Fig. 5 SEM cross section of the alteration layer formed on ISG exposed for 209 days to $\mathrm{pH} 9$ solution saturated with silica at $90^{\circ} \mathrm{C}$. (reproduced with permission from ref. ${ }^{35}$, copyright Elsevier 2017)

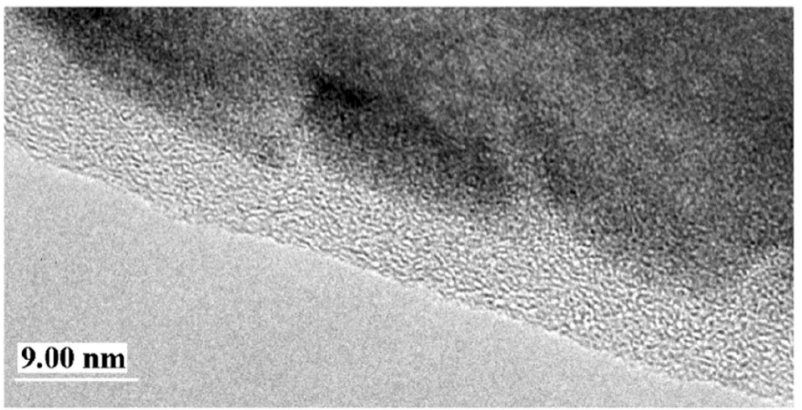

Fig. 6 TEM cross section of $\left(\mathrm{Ca}\left(\mathrm{U}_{0.5} \mathrm{Ce}_{0.25} \mathrm{Hf}_{0.25}\right) \mathrm{Ti}_{2} \mathrm{O}_{7}\right)$ exposed for 835 days at $\mathrm{RT}$ in $\mathrm{pH} 4$ potassium acid phthalate buffer with $0.005 \mathrm{M}$ $\mathrm{HCl}$. (reproduced with permission from ref. ${ }^{196}$, copyright American Chemical Society 2004) 
Zr...), but the rate slows rapidly. If stage III sets in, the rate increases dramatically again, potentially close to but never higher than the initial rate. Some ceramics exhibit similar dissolution kinetics as glass with the initial rapid dissolution stage and a slow dissolution stage when approaching to equilibrium conditions (Fig. 2b-1)). The dramatic increase in the rate in stage III dissolution is rarely described in the ceramics corrosion literature, but the transformation of amorphous alteration layer to crystalline phases is common for ceramics after exposure in aqueous environments for a long period of time. Similar to glasses, this process may cause a delayed increase in the rate of alteration of the ceramic material. Metals react quickly with an exponential decrease in corrosion rate as the passive film forms, eventually reaching a low steady state passive dissolution rate where the rate of metal oxidation and film formation at the metal/oxide interface equals the rate of film dissolution at the oxide/solution interface. The rate will then increase again if localized corrosion initiates. All three materials classes may require an incubation time related to interaction of the environment with the surface to change it chemically, physically, structurally, or to introduce defects. On the other hand, stage III of glass corrosion is usually global, occurring equally across the exposed surface, whereas passive film breakdown on metals is local.

Typical rates of corrosion can be compared by considering reaction rates in units of $\mathrm{m} \mathrm{yr}^{-1}$. The corrosion rate of glass is usually measured at $90^{\circ} \mathrm{C}$, and typical values for the initial forward reaction rate and the residual reaction rate are 1 and $2 \times 10^{-4} \mathrm{~g}$ $\mathrm{m}^{-2} \mathrm{~d}^{-1}$, respectively. Assuming a glass density of $2.7 \mathrm{~g} \mathrm{~cm}^{-3}$, this corresponds to corrosion rates of $1.4 \times 10^{-4}$ and $3 \times 10^{-8} \mathrm{~m} \mathrm{yr}^{-1}$, respectively. Considering that the rates at RT are $\sim 2$ orders of magnitude slower than at $90^{\circ} \mathrm{C}{ }^{197}$, the RT residual rate of glass corrosion is on the order of $10^{-10} \mathrm{~m} \mathrm{yr}^{-1}$. For a stagnant solution, the transition from the initial rate to transient rate takes a few weeks to a few months, but the transition is extended in the presence of flow, possibly indefinitely.

Ceramics in general display slower corrosion rates than glass as a result of structural confinement in crystalline lattices, which varies depending on the structure and composition. A typical value of the initial corrosion rate of ceramics measured at $90^{\circ} \mathrm{C}$ is on the order of $10^{-1}-10^{-2} \mathrm{~g} \mathrm{~m}^{-2} \mathrm{~d}^{-1}$, which equate to $10^{-5}-10^{-6}$ $\mathrm{m} \mathrm{yr}^{-1}$. The steady state corrosion rate of titanate-based ceramics is on the order of $10^{-3}-10^{-5} \mathrm{~g} \mathrm{~m}^{-2} \mathrm{~d}^{-1}$, equivalent to $10^{-7}-10^{-9}$ $\mathrm{m} \mathrm{yr}^{-1}$, respectively. ${ }^{198,199}$ Both $\mathrm{pH}$ and temperature significantly impact the corrosion rate of ceramics, and several orders of magnitude difference in the corrosion rate can be observed from highly acidic to near-neutral $\mathrm{pH}$ values. The time to achieve steady state varies from days to years.

Metal passivation kinetics decrease exponentially with time so there is no true initial rate. The measured current density on a freshly bared metal surface undergoing passivation depends on the timescale at which the measurement is made, and has been measured to be as high as $100 \mathrm{~A} \mathrm{~cm}^{-2}$ using special thin film breaking electrodes that allow measurements on the timescale of $\mu \mathrm{s}^{200,201}$ This current density equates to the extraordinary rate of $1 \times 10^{3} \mathrm{~m} \mathrm{yr}^{-1}$ at these very short times. However, the rate decays rapidly and the steady state passive current density for a good CRA, which at RT might be on the order of $10^{-8} \mathrm{~A} \mathrm{~cm}^{-2}$ or $10^{-7} \mathrm{~m}$ $\mathrm{yr}^{-1}$, could be achieved within hours or days.

The comparison of the rates is instructive, as shown Fig. 7. The rates of ceramic corrosion are the lowest and those of metal corrosion the greatest, but the values of residual or steady state corrosion are within a few orders of magnitude. Furthermore, the steady state rates are all quite small, which highlights the difficulty in making measurements. The electrochemical nature of metallic corrosion facilitates the measurement of metal corrosion rates, both the low steady state rates found for CRAs and the high rates found at very short times.

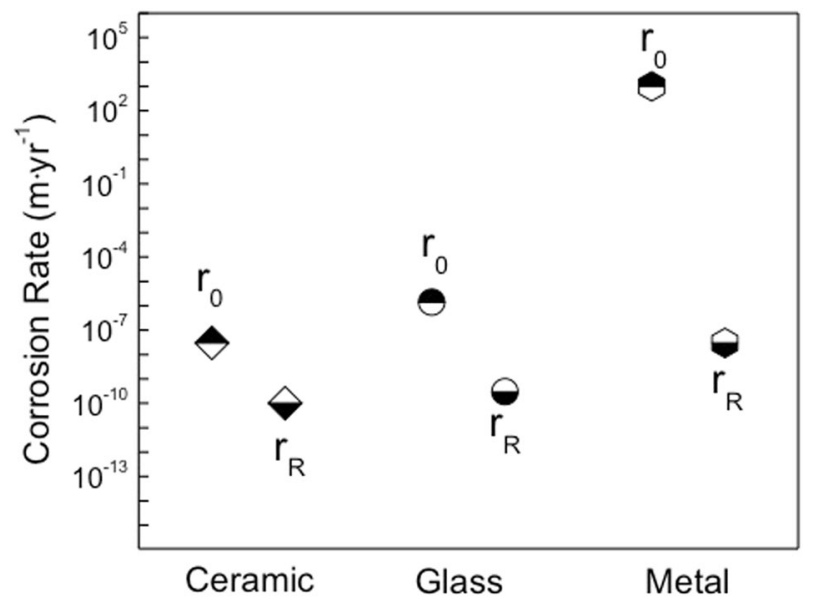

Fig. 7 Summary of estimates of initial rates of corrosion, $r_{0}$, and residual or steady state rates, $r_{R}$, for ceramics, glasses and corrosionresistant metal alloys. The very high initial rate shown for metal passivation is a consequence of the very short timescale $(\mu \mathrm{s})$ over which such rates can be measured for metals

\section{Rate-controlling processes vary}

Mass transport in the passivating layer is often rate controlling in glass and ceramic corrosion. The thin film passivity of metals is usually controlled by oxide defect chemistry and charge carrier densities governing interfacial reactions or transport through the oxide, and rarely by mass transport control through the bulk solution phase, which, however, can be an important factor in thick film passivation. Alteration layers on glass and ceramics might form by dissolution/precipitation or direct reorganization, depending on many intrinsic and extrinsic factors. Precipitated films on metals are not protective; passive films form directly on the surface. Dissolution, particularly in the early stages, can be incongruent for all three material classes and depends on the environment, and this has a large effect on the passive film/ alteration layer composition. Dissolution of metals is always oxidative. Ceramics can undergo oxidative or reductive dissolution, or dissolve without redox reactions by ion exchange or chemical dissolution with no charge transfer. Silicate glasses mostly undergo chemical dissolution and ion exchange, with oxidative or reductive processes limited to the attack and transport of particular multivalent ions in certain waste glasses.

The processes of delayed acceleration of corrosion are different All three materials can exhibit an acceleration in corrosion following a period at a much reduced rate. The passive film on many metals breaks down locally in aggressive environments containing halides as the result of local thinning, voiding and collapse, or stress-induced rupture. The attack is sustained by local changes in environment driven by the physical separation of the anodic and cathodic reactions. Glass corrosion has been shown to accelerate concurrent with the precipitation of zeolites, magnesium silicates, $\mathrm{CSH}$, or iron silicates for some conditions and compositions. These phases remove silicon and/or aluminum from the local solution, which can either disrupt the passivating properties of an alteration layer or drive the reaction of the glass itself to much higher kinetic rates. In crystalline ceramics, the transformation of a passivating film to new phases may lead to accelerated corrosion similar to the stage III in glass corrosion due to increased solution transport in the newly formed crystalline film. 


\section{Critical factors are similar}

The corrosion reactions for glasses, ceramics, and metals are all driven by thermodynamic factors as these materials are typically far from equilibrium during natural exposure. Material composition plays a dominant role in determining corrosion rate for all three material classes. Material structure plays a role when reactions at the interface are the rate-limiting step in the corrosion process. Environmental parameters are critical in all three cases with $\mathrm{pH}$, temperature, and the presence of aggressive or protective ionic species in the environment all being important. Anions in the environment dominate the corrosion of metals, while both anions and cations can significantly influence ceramic and glass corrosion. A minimum dissolution rate is often observed at near-neutral $\mathrm{pH}$ for all three materials, though many metals exhibit continued decrease in rate with increasing $\mathrm{pH}$. Electrode potential is a major driving force for metals and electrochemically active ceramics. Processing history is critical for determining the microstructure of metals and ceramics and thereby corrosion resistance. For glass, the structure and properties including corrosion rate can be slightly impacted by thermal history. The most significant impacts of thermal history of waste glass are the result of macroscopic cracking, which increases the effective surface area for glass corrosion ${ }^{12,202}$ and phase changes which alter the residual glass composition. ${ }^{203}$

\section{Suggestions to advance the current knowledge}

The corrosion behaviors of the three material classes-glass, ceramics, and metals-have been studied independently; the comparison of corrosion mechanisms found or proposed in each material class clearly shows similarities in their degradation behavior. The most significant commonality is the initial formation of a protective surface layer, involving reorganization and enrichment of the film towards some quasi-steady state configuration of both structure and composition. However, factors controlling the breakdown processes are different. This suggests that a major breakthrough in scientific understanding of corrosion behavior could be brought about by adapting knowledge or analytical and modeling methods from other material fields.

Corrosion has been studied extensively in each material field, but many fundamental questions remain elusive. Such questions are unlikely to be answered if they are studied with the same conventional techniques that have been broadly used in the past. In that sense, advanced techniques that have been used in one material research field could be adopted in other material fields to discover new insights. For example, the isotope labeling and exchange methods commonly used in glass corrosion studies could be employed in metal corrosion research to study the fate of oxidized metal ions and in ceramic corrosion to study the atom transport and ion exchange processes. Also, atom probe topography, which has been widely used for atomic level chemical analysis in metallurgy, can be applied to the precision depth profiling across the alteration layer on metals, glass and ceramics, and the elemental mapping of the alteration layer/bulk glass interfacial region. Similarly, computational methods used to predict and visualize glass corrosion could be utilized for ceramic corrosion. Of course, the application of analytical methods developed in one material field to other materials might not be simple, but the potential return would be high if obstacles could be resolved or circumvented.

The comparison of surface degradation mechanisms also highlights new questions that have not yet been considered in depth. For example, the alteration layer on glass cannot be in the equilibrium state because it is formed in non-equilibrium reaction conditions on a substrate that is itself a non-equilibrium material. The composition and density of the alteration layer are quite different from the bulk glass, so it is likely to contain residual stress. ${ }^{204}$ When the layer thickness is small, the stress is small and the layer would be stable. However, as the layer thickness grows, the residual stress grows due to the density difference and eventually could lead to catastrophic failure. In that case, the interfacial stress effect should be considered in the thermodynamics of the alteration layer growth and stability. Such interfacial stress effects on bond parameters of the glass network could be studied using new spectroscopic techniques. ${ }^{205,206}$ Similar arguments or approaches could pertain to surface films formed during the degradation of other materials. The competitive adsorption of species from the environment and their effects on surface stresses is an area ripe for advancement.

The alteration layers formed in non-equilibrium conditions could be locally inhomogeneous, not just through the depth or thickness, but also laterally. Therefore, local fluctuations of thermodynamic and/or transport properties could play critical roles in the overall degradation behavior. This is ubiquitous in metal corrosion, and it is possible that the same effects exist in the corrosion of glass and ceramic materials to a certain degree. Therefore, interdisciplinary or trans-disciplinary collaborations across different material fields will bring new insights into complicated material degradation mechanisms beyond what one research field has been able to achieve.

Another issue relates to the fact that environments in corrosion processes are often confined in nm-dimensional spaces, such as in the alteration film on glass or in incipient pits in metals. Solution phase characteristics such as $\mathrm{pH}$, concentration, and activity have been defined for bulk phases, and advances are required in the fundamental understanding of these parameters for their application in such small, confined volumes.

Finally, the use of common modeling approaches for the corrosion of the different materials has significant potential to provide new insights. The multiscale nature of corrosion, where atomistic surface processes (which are difficult or impossible to identify by lab experiments) end up in macroscopic dissolution (which is accurately measurable), requires modeling and crossvalidation on all length scales, in which atomic level models ${ }^{207}$ typically inform the meso and macroscopic scales. Commonalities in modeling of the different materials exist, especially on the most fundamental quantum mechanical and the most macroscopic rate theory scales, with opportunities for cross-fertilization, particularly at the intermediate mesoscale.

On the most fundamental atomic scale, quantum mechanical methods, typically within density functional theory, are routinely used to study the reaction pathways and energy barriers for all materials, from the hydrolysis reactions in network glasses ${ }^{70}$ and minerals $^{208}$ to electrochemical processes of metal corrosion. ${ }^{209,210}$ Recent developments involving more realistic modeling of solvent effects $^{211,212}$ offer significant potential for further exploration. On the macroscopic scale within rate theory, the change in concentration and material at the surface is modeled by differential equation systems, governed by diffusion and reaction constants that are fitted to experiments or calculated by atomistic modeling, which has been demonstrated for ceramics (see Fundamentals of kinetics of crystal dissolution), glasses, ${ }^{213}$ and uniform metal corrosion. ${ }^{214}$ On the intermediate level, materialspecific differences exist, which offer the greatest potential for knowledge transfer between the fields. For example, within glass corrosion, classical and ab initio molecular dynamics (MD) simulations are prominently used to generate realistic bulk and surface structures of waste glasses, ${ }^{215-218}$ including the nanoporous gel layer structures during glass corrosion. ${ }^{219,220}$ To a lesser degree, MD has also been used to describe ceramics and metal corrosion and inhibition. ${ }^{221}$ MD has not been more widely used because of the limited availability of interatomic potentials to describe the heterogeneous interfaces. The expected development of more accurate potentials will open up the possibility to study reaction, diffusion, defect formation, and migration at the extended atomic scale for more materials. ${ }^{207}$ Modeling at the 
intermediate length and times scale is most prominently represented by stochastic models based on cellular automata and Monte Carlo modeling, 222,223 which are especially appropriate to model pitting corrosion, ${ }^{222}$ and gel layer microstructure evolution during glass corrosion, ${ }^{224}$ but have been explored to a much lesser degree for ceramic corrosion.

Exploiting the full range of modeling methods developed for the different materials classes can potentially provide unprecedented insights in not only the mechanisms of corrosion of these materials but also in the deliberate design of new compositions and structures.

\section{CONCLUSIONS}

Oxide glass, crystalline ceramics, and metals have different structure, bonding, and (usually) different composition, yet they all can degrade upon exposure to an aqueous environment. This review provides a high level overview of the corrosion mechanisms of each type of material, and then describes similarities and differences.

- The form of the kinetics for each is similar, with a rapid initial reaction followed by slowing as the result of (or simply concurrent with) the formation of a surface film. The corrosion rate can increase again if the conditions promote a loss of protection of the surface passivation or alteration layer.

- The disruption of passivating mechanisms happens globally on glass and locally on metals. The loss of protection of the surface film leading to accelerated corrosion is less well understood on crystalline ceramics.

- Mass transport plays an important role in all materials, and the dissolution processes include chemical dissolution, ion exchange, and electrochemical reactions.

- Synergistic interactions between researchers studying the corrosion of the different materials classes should lead to cross-fertilization and advances in understanding of the fundamental mechanisms of degradation. Possibilities exist in the areas of advanced characterization including in situ methods and modeling at different relevant length scales.

\section{ACKNOWLEDGEMENTS}

This work was supported as part of the Center for Performance and Design of Nuclear Waste Forms and Containers, an Energy Frontier Research Center funded by the U.S. Department of Energy, Office of Science, Basic Energy Sciences under Award \# DESC0016584. The Pacific Northwest National Laboratory is operated by Battelle for the DOE under contract DE-AC05-76RL01830. Conversations with all members of WastePD are greatly appreciated. This work was supported as part of the Center for Performance and Design of Nuclear Waste Forms and Containers, an Energy Frontier Research Center funded by the U.S. Department of Energy, Office of Science, Basic Energy Sciences under Award \# DE-SC0016584.

\section{AUTHOR CONTRIBUTIONS}

All of the listed authors contributed to the writing of this review paper. G.S.F. coordinated the effort and merged the contributions. The section on glass was written primarily by J.D.V., S.G., and J.V.R., the section on ceramics was written primarily by J.L. and J.W., the section on metals was written primarily by J.R.S. and G.S. F. All contributed to the writing of the last section of this paper.

\section{ADDITIONAL INFORMATION}

Competing interests: The authors declare no competing interests.

Publisher's note: Springer Nature remains neutral with regard to jurisdictional claims in published maps and institutional affiliations.

\section{REFERENCES}

1. Frankel, G. S., Vienna, J. \& Lian, J. WastePD, an innovative center on materials degradation. npj Mater. Degrad. 1, 5 (2017).

2. Vienna, J. D., Ryan, J. V., Gin, S. \& Inagaki, Y. Current understanding and remaining challenges in modeling long-term degradation of borosilicate nuclear waste glasses. Int. J. Appl. Glass Sci. 4, 283-294 (2013).

3. Jantzen, C. M., Brown, K. G. \& Pickett, J. B. Durable glass for thousands of years. Int. J. Appl. Glass Sci. 25, 38-62 (2010).

4. Gin, S. Open scientific questions about nuclear glass corrosion. Procedia Mater. Sci. 7, 163-171 (2014).

5. Fournier, M. et al. Glass dissolution rate measurement and calculation revisited. J. Nucl. Mater. 476, 140-154 (2016).

6. Gin, S. et al. An international initiative on long-term behavior of high-level nuclear waste glass. Mater. Today 16, 243-248 (2013).

7. Inagaki, K., Furuya, H., Idemitsu, K. \& Arima, T. Review of waste glass corrosion and associated radionuclide release as a part of safety assessment of entire disposal system. Prog. Nucl. Energ. 32, 501-508 (1998).

8. Bunker, B. C. Molecular mechanisms for corrosion of silica and silicate glasses. Non-Cryst. Solids 179, 300-308 (1994).

9. Van Iseghem, P. et al. in Ceramic Transactions Vol. 207 (eds Cosi, A. \& Ohji, T.) 115-126 (American Ceramic Society, Westerville, OH, 2009).

10. Grambow, B. Nuclear waste glasses - How durable? Elements 2, 357-364 (2006).

11. Parruzot, B. Altération des verres basaltiques dans des environnements confinés: analogie avec le stockage géologique des verres nucléaires [Basaltic glass alteration in confined environment: analogy to nuclear waste glass geological repository]. PhD thesis, Univ. Montpellier, (2014).

12. Verney-Carron, A., Gin, S. \& Libourel, G. Archaeological analogs and the future of nuclear waste glass. J. Nucl. Mater. 406, 365-370 (2010).

13. Ferrand, K., Liu, S. \& Lemmens, K. The effect of Ordinary Portland Cement on nuclear waste glass dissolution. Procedia Mat. Sci. 7, 223-229 (2014).

14. Maeda, T., Ohmori, H., Mitsui, S. \& Banba, T. Corrosion behavior of simulated HLW glass in the presence of magnesium ion. Int. J. Corros. 2011, 796457 (2011).

15. Debure, M., Frugier, P., De Windt, L. \& Gin, S. Borosilicate glass alteration driven by magnesium carbonates. J. Nucl. Mater. 420, 347-361 (2012).

16. Debure, M., De Windt, L., Frugier, P. \& Gin, S. HLW glass dissolution in the presence of magnesium carbonate: diffusion cell experiment and coupled modeling of diffusion and geochemical interactions. J. Nucl. Mater. 443, 507-521 (2013).

17. Debure, M., De Windt, L., Frugier, P., Gin, S. \& Vieillard, P. Mineralogy and thermodynamic properties of magnesium phyllosilicates formed during the alteration of a simplified nuclear glass. J. Nucl. Mater. 475, 255-265 (2016).

18. Michelin, A. et al. Silicate glass alteration enhanced by iron: origin and long-term implications. Environ. Sci. Technol. 47, 750-756 (2013).

19. Rebiscoul, D. et al. Reactive transport processes occurring during nuclear glass alteration in presence of magnetite. Appl. Geochem. 58, 26-37 (2015).

20. Reiser, J. T et al. Scientific basis for nuclear waste management XXXVIII. In MRS Symposium Proceedings, Vol. 1744 (eds Josef Matyáš, Stéphane Gin, Robert Jubin, Eric Vance) 139-144 (Materials Research Society, Warrendale, 2015).

21. Dillmann, P., Gin, S., Neff, D., Gentaz, L. \& Rebiscoul, D. Effect of natural and synthetic iron corrosion products on silicate glass alteration processes. Geochim. Cosmochim. Acta 172, 287-305 (2016).

22. Fournier, M., Gin, S. \& Frugier, P. Resumption of nuclear glass alteration: state of the art. J. Nucl. Mater. 448, 348-363 (2014).

23. Ebert, W. L. \& Bates, J. K. Scientific basis for nuclear waste management XIV. In Materials Research Society Symposium Proceedings (ed Teofilo A. Abrajano) (Materials Research Society, Boston, 1991) 89-98. .

24. Inagaki, Y. et al. Aqueous alteration of Japanese simulated waste glass P0798: effects of alteration-phase formation on alteration rate and cesium retention. $J$. Nucl. Mater. 354, 171-184 (2006).

25. Muller, I. S., Ribet, S., Pegg, I. L., Gin, S. \& Frugier, P. in Ceramic Transactions Vol. 176 191-199 (American Ceramic Society, Westerville, 2006).

26. Gin, S. Scientific Basis for Nuclear Waste Management XXIV. In Materials Research Society Symposium Proceedings (eds Hart, K. P. \& Lumpkin, G. R.) 207-215 (Materials Research Society, Warrendale, 2000).

27. Rebiscoul, D., Frugier, P., Gin, S. SpringerAmpamp; Ayral, A. Protective properties and dissolution ability of the gel formed during nuclear glass alteration. J. Nucl. Mater. 342, 26-34 (2005).

28. Gin, S. et al. The controversial role of inter-diffusion in glass alteration. Chem. Geol. 440, 115-123 (2016).

29. Gin, S., Ribet, I. \& Couillard, M. Role and properties of the gel formed during nuclear glass alteration: importance of gel formation conditions. J. Nucl. Mater. 298, 1-10 (2001).

30. Bunker, B. C. Molecular mechanisms for corrosion of silica and silicate-glasses. J. Non-Cryst. Solids 179, 300-308 (1994). 
31. Valle, N. et al. Elemental and isotopic (Si-29 and O-18) tracing of glass alteration mechanisms. Geochim. Cosmochim. Acta 74, 3412-3431 (2010).

32. Geisler, T. et al. Aqueous corrosion of borosilicate glass under acidic conditions: a new corrosion mechanism. J. Non-Cryst. Solids 356, 1458-1465 (2010).

33. Geisler, T. et al. The mechanism of borosilicate glass corrosion revisited. Geochim. Cosmochim. Acta 158, 112-129 (2015).

34. Gin, S. et al. The fate of silicon during glass corrosion under alkaline conditions: a mechanistic and kinetic study with the International Simple Glass. Geochim. Cosmochim. Acta 151, 68-85 (2015).

35. Gin, S. et al. Atom-probe tomography, TEM and ToF-SIMS study of borosilicate glass alteration rim: a multiscale approach to investigating rate-limiting mechanisms. Geochim. Cosmochim. Acta 202, 57-76 (2017).

36. Gin, S. et al. Origin and consequences of silicate glass passivation by surface layers. Nat. Commun. 6, 8 (2015).

37. Hellmann, R. et al. Nanometre-scale evidence for interfacial dissolutionreprecipitation control of silicate glass corrosion. Nat. Mater. 14, 307-311 (2015).

38. Delage, F., Ghaleb, D., Dussossoy, J. L., Chevallier, O. \& Vernaz, E. A mechanistic model for understanding nuclear waste glass dissolution. J. Nucl. Mater. 190, 191-197 (1992).

39. Grambow, B. \& Muller, R. First-order dissolution rate law and the role of surface layers in glass performance assessment. J. Nucl. Mater. 298, 112-124 (2001).

40. Gin, S., Beaudoux, X., Angeli, F., Jegou, C. \& Godon, N. Effect of composition on the short-term and long-term dissolution rates of ten borosilicate glasses of increasing complexity from 3 to 30 oxides. J. Non-Cryst. Solids 358, 2559-2570 (2012).

41. Gin, S., Frugier, P., Jollivet, P., Bruguier, F. \& Curti, E. New insight into the residual rate of borosilicate glasses: effect of $\mathrm{S} / \mathrm{V}$ and glass composition. Int. J. Appl. Glass Sci. 4, 371-382 (2013).

42. Frugier, P. et al. SON68 nuclear glass dissolution kinetics: current state of knowledge and basis of the new GRAAL model. J. Nucl. Mater. 380, 8-21 (2008).

43. Jollivet, P. et al. Investigation of gel porosity clogging during glass leaching. J. Non-Cryst. Solids 354, 4952-4958 (2008).

44. Cailleteau, C. et al. Insight into silicate-glass corrosion mechanisms. Nat. Mater. 7, 978-983 (2008).

45. Gin, S., Ryan, J. V., Schreiber, D. K., Neeway, J. \& Cabie, M. Contribution of atomprobe tomography to a better understanding of glass alteration mechanisms: application to a nuclear glass specimen altered 25 years in a granitic environment. Chem. Geol. 349, 99-109 (2013).

46. Cailleteau, C., Devreux, F., Spalla, O., Angeli, F. \& Gin, S. Why do certain glasses with a high dissolution rate undergo a low degree of corrosion? J. Phys. Chem. C. 115, 5846-5855 (2011).

47. Gin, $S$ et al. Origin and consequences of silicate glass passivation by surface layers. Nat. Commun. 6, 6360 (2015).

48. Ledieu, A., Devreux, F., Barboux, P., Sicard, L. \& Spalla, O. Leaching of borosilicate glasses. I. Experiments. J. Non-Cryst. Solids 343, 3-12 (2004).

49. Wild, B. et al. pH-dependent control of feldspar dissolution rate by altered surface layers. Chem. Geol. 442, 148-159 (2016).

50. Crovisier, J. L., Advocat, T. \& Dussossoy, J. L. Nature and role of natural alteration gels formed on the surface of ancient volcanic glasses (Natural analogs of waste containment glasses). J. Nucl. Mater. 321, 91-109 (2003).

51. Fournier, M., Gin, S. \& Frugier, P. Resumption of nuclear glass alteration: state of the art. J. Nucl. Mater. 448, 348-363 (2014).

52. Ribet, S., Muller, I. S., Pegg, I. L., Gin, S. \& Frugier, P. Scientific basis for nuclear waste management XXVIII . In Materials Research Society Symposium Proceedings (eds Hanchar, J. M., StroesGascoyne, S. \& Browning, L.) 309-314 (Materials Research Society, Warrendale, 2004).

53. Fournier, M., Gin, S., Frugier, P. \& Mercado-Depierre, S. Contribution of zeoliteseeded experiments to the understanding of resumption of glass alteration. npj Mater. Degrad. 1, 17 (2017).

54. Fett, T., Guin, J. P. \& Wiederhorn, S. M. Stresses in ion-exchange layers of sodalime-silicate glass. Fatigue Fract. Eng. Mater. Struct. 28, 507-514 (2005).

55. Barkatt, A. et al. Leach Rate Excursions in Borosilicate Glasses - Effects of Glass and Leachant Composition. Vol. 212 (Materials Research Soc, Warrendale, 1991).

56. Sang, J. C., Barkatt, A., Talmy, I. G. \& Norr, M. K. Scientific basis for nuclear waste management XVI. In Materials Research Society Symposium Proceedings (eds Interrante, C. G. \& Pabalan, R. T.) 583-589 (Materials Research Society, Warrendale, 1993).

57. Neill, L. G., et al. Various effects of magnetite on international simple glass (ISG) dissolution: implications for the long-term durability of nuclear glasses. npj Mater. Degrad. 1, 1 (2017).

58. Peuget, S., Delaye, J. M. \& Jegou, C. Specific outcomes of the research on the radiation stability of the French nuclear glass towards alpha decay accumulation. J. Nucl. Mater. 444, 76-91 (2014).

59. Tribet, $M$ et al. 2nd international summer school on nuclear glass wasteform: structure, properties and long-term behavior. In Procedia Material Science (eds Angeli, F. et al.) 209-215 (Elsevier Science BV, Amsterdam, 2014).
60. Weber, W. J. et al. Radiation effects in glasses used for immobilization of highlevel waste and plutonium disposition. J. Mater. Res. 12, 1946-1978 (1997).

61. Weber, W. J. Radiation and thermal ageing of nuclear waste glass. Procedia Mater. Sci. 7, 237-246 (2014).

62. McGrail, B. P. et al. The structure of $\mathrm{Na}_{2} \mathrm{O}-\mathrm{Al}_{2} \mathrm{O}_{3}-\mathrm{SiO}_{2}$ glass: impact on sodium ion exchange in $\mathrm{H}_{2} \mathrm{O}$ and $\mathrm{D}_{2} \mathrm{O}$. J. Non-Cryst. Solids 296, 10-26 (2001).

63. Shutthanandan, $V$ et al. 16th international conference on the application of accelerators in research and industry. In AIP Conference Proceedings (eds Duggan, J. L. \& Morgan, I. L.) 454-457 (American Inst. of Physics, Denton, 2001).

64. Icenhower, J. P., McGrail, B. P. \& Luttge, A. Origins of deviations from transitionstate theory: affects of ion-exchange kinetics in glass. Geochim. Cosmochim. Acta 66, A351-A351 (2002).

65. Kaneko, T. An ion-exchange model of glass leaching. J. Mater. Sci. Lett. 4, 631-634 (1985).

66. McGrail, B. P. et al. lon-Exchange Processes and Mechanisms in Glasses. Report No. PNNL-13717, (Pacific Northwest National Laboratory, Richland, 1998).

67. Oelkers, E. H., Golubev, S. V., Chairat, C., Pokrovsky, O. S. \& Schott, J. The surface chemistry of multi-oxide silicates. Geochim. Cosmochim. Acta 73, 4617-4634 (2009).

68. Neeway, J. J. et al. lon-exchange interdiffusion model with potential application to long-term nuclear waste glass performance. J. Phys. Chem. C. 120, 9374-9384 (2016).

69. Bunker, B. C., Arnold, G. W., Day, D. E. \& Bray, P. J. The effect of molecularstructure on borosilicate glass leaching. J. Non-Cryst. Solids 87, 226-253 (1986).

70. Zapol, P., He, H. Y., Kwon, K. D. \& Criscenti, L. J. First-principles study of hydrolysis reaction barriers in a sodium borosilicate glass. Int. J. Appl. Glass Sci. 4, 395-407 (2013).

71. Ford, D. C., He, H. \& Zapol, P. Density Functional Theory Calculations of Hydrolysis Reactions on a Sodium Borosilicate Glass Surface. Report No. FCRDMRWFD-2015-000149, (Argonne National Laboratory, Argonne, 2015).

72. Kerisit, S. N. \& Pierce, E. M. Monte Carlo simulations of the dissolution of borosilicate and aluminoborosilicate glasses in dilute conditions. Geochim. Cosmochim. Acta 75, 5296-5309 (2011).

73. Kerisit, S., Ryan, J. V. \& Pierce, E. M. Monte Carlo simulations of the corrosion of aluminoborosilicate glasses. J. Non-Cryst. Solids 378, 273-281 (2013).

74. Frugier, P., Martin, C., Ribet, I., Advocat, T. \& Gin, S. The effect of composition on the leaching of three nuclear waste glasses: R7T7, AVM and VRZ. J. Nucl. Mater. 346, 194-207 (2005).

75. Carriere, C. et al. Influence of iron corrosion on nuclear glass alteration processes: nanoscale investigations of the iron-bearing phases. Corr. Eng. Sci. Tech. 53, 166-172 (2017)

76. Ebert, W. L. \& Jerden, J. L. Jr. Implementation of the ANL Stage 3 Glass Dissolution Model. Report No. FCRD-MRWFD-2016-000296. (Argonne National Laboratory, Argonne, 2016).

77. Jantzen, C. M., Trivelpiece, C. L., Crawford, C. L., Pareizs, J. M. \& Pickett, J. B. Accelerated leach testing of glass (ALTGLASS): II. Mineralization of hydrogels by leachate strong bases. Int. J. Appl. Glass Sci. 8, 84-96 (2017).

78. Ribet, S, Muller, I. S, Pegg, I. L, Gin, S. \& Frugier, P. Scientific basis for nuclear waste management XXVIII. In Materials Research Society Symposium Proceedings (eds Hanchar, J. M., Stroes-Gascoyne, S., Browning, L.) 309-314 (Materials Research Society, San Francisco, 2004).

79. Strachan, D. M. \& Croak, T. L. Compositional effects on long-term dissolution of borosilicate glass. J. Non-Cryst. Solids 272, 22-33 (2000).

80. Fournier, M. G. S., Frugier, P. \& Mercado-Depierre, S. Contribution of zeoliteseeded experiments to the understanding of resumption of glass alteration. npj Mater. Degrad. 1, 17 (2017).

81. Rechard, R. P et al. Basis for Identification of Disposal Options for Research and Development for Spent Nuclear Fuel and High-level Waste. Report No. SAND2011-3781P (Sandia National Laboratories, Albuquerque, 2011).

82. de Combarieu, G. et al. Glass-iron-clay interactions in a radioactive waste geological disposal: an integrated laboratory-scale experiment. Appl. Geochem. 26, 65-79 (2011).

83. Michelin, A. et al. Effect of iron metal and siderite on the durability of simulated archeological glassy material. Corros. Sci. 76, 403-414 (2013).

84. Arena, $\mathrm{H}$. et al. Impact of $\mathrm{Zn}, \mathrm{Mg}, \mathrm{Ni}$ and $\mathrm{Co}$ elements on glass alteration: additive effects. J. Nucl. Mater. 470, 55-67 (2016).

85. Debure, M., De Windt, L., Frugier, P. \& Gin, S. HLW glass dissolution in the presence of magnesium carbonate: diffusion cell experiment and coupled modeling of diffusion and geochemical interactions. J. Nucl. Mater. 443, 507-521 (2013).

86. Verney-Carron, A., Gin, S., Frugier, P. \& Libourel, G. Long-term modeling of alteration-transport coupling: application to a fractured Roman glass. Geochim. Cosmochim. Acta 74, 2291-2315 (2010).

87. Verney-Carron, A., Gin, S. \& Libourel, G. A fractured roman glass block altered for 1800 years in seawater: analogy with nuclear waste glass in a deep geological repository. Geochim. Cosmochim. Acta 72, 5372-5385 (2008). 
88. Berner, R. A. Rate control of mineral dissolution under earth surface conditions. Am. J. Sci. 278, 1235-1252 (1978).

89. Brantley, S. L. in Kinetics of Water-Rock Interaction (eds Brantley, B., Kubicki, J. \& White, A.) 151-210 (Springer-Verlag, Berlin, 2008).

90. Lasaga, A. C. in Chemical Weathering Rates of Silicate Minerals. Vol. of 31 Reviews in Mineralogy (eds White, A.F. \& Brantley, S.L.) 23-86 (Mineralogical Society of America, Chantilly, 1995).

91. Putnis, A. in Thermodynamics and Kinetics of Water-Rock Interaction. Vol. 70 of Reviews in Mineralogy \& Geochemistry (eds Oelkers, E.H. \& Schott, J.) 87-124 (Mineralogical Society of America, Chantilly, 2009).

92. Schott, J., Pokrovsky, O. S. \& Oelkers, E. H. in Thermodynamics and Kinetics of Water-Rock Interaction. Vol. 70 Reviews in Mineralogy \& Geochemistry (eds Oelkersrs E. H. \& Schott J.) 207-258 (Mineralogical Society of America, Chantilly, 2009).

93. Walther, J. V. Relation between rates of aluminosilicate mineral dissolution, $\mathrm{pH}$ temperature, and surface charge. Am. J. Sci. 296, 693-728 (1996).

94. Burgess, J. Ions in Solution-Basic Principles of Chemical Interaction 2nd edn (Woodhead Publishing, Cambridge, 1999).

95. Hellmann, R. \& Tisserand, D. Dissolution kinetics as a function of the Gibbs free energy of reaction: an experimental study based on albite feldspar. Geochim. Cosmochim. Acta 70, 364-383 (2006).

96. White, W. B. in Corrosion of Glass, Ceramics and Superconductors (eds Clark, D.E. \& Zoitos, B.K.) (Noyes, Norwich, 1992).

97. Aagaard, P. \& Helgeson, H. C. Thermodynamic and kinetic constraints on reaction-rates among minerals and aqueous-solutions .1. theoretical considerations. Am. J. Sci. 282, 237-285 (1982).

98. Lasaga, A. C. in Kinetics of Geochemical Processes Vol. 8 (eds Lasaga, A.C. \& R. J. Kirkpatrick, R.J.) 135-169 (Minerallogical Society of America, Chantilly, 1981).

99. Gautier, J. M., Oelkers, E. H. \& Schott, J. Experimental-study of k-feldspar dissolution rates as a function of chemical affinity at 150-degrees-c and ph-9. Geochim. Cosmochim. Acta 58, 4549-4560 (1994).

100. Oelkers, E. H. \& Schott, J. Experimental study of anorthite dissolution and the relative mechanism of feldspar hydrolysis. Geochim. Cosmochim. Acta 59, 5039-5053 (1995).

101. Oelkers, E. H., Schott, J. \& Devidal, J. L. The effect of aluminum, ph, and chemical affinity on the rates of aluminosilicate dissolution reactions. Geochim. Cosmochim. Acta 58, 2011-2024 (1994).

102. Nagy, K. L., Blum, A. E. \& Lasaga, A. C. Dissolution and precipitation kinetics of kaolinite at 80-degrees-c and ph 3 - the dependence on solution saturation state. Am. J. Sci. 291, 649-686 (1991).

103. Burch, T. E., Nagy, K. L. \& Lasaga, A. C. Free-energy dependence of albite dissolution kinetics at 80-degrees-c and ph 8.8. Chem. Geol. 105, 137-162 (1993).

104. Luttge, A. Crystal dissolution kinetics and Gibbs free energy. J. Electron Spectrosc Relat. Phenom. 150, 248-259 (2006).

105. Lasaga, A. C. \& Luttge, A. Variation of crystal dissolution rate based on a dissolution stepwave model. Science 291, 2400-2404 (2001).

106. Diedrich, T., Dybowska, A., Schott, J., Valsarni-Jones, E. \& Oelkers, E. H. The dissolution rates of $\mathrm{SiO}_{2}$ nanoparticles as a function of particle size. Environ. Sci. Technol. 46, 4909-4915 (2012).

107. Swaminathan, P., Sivaramakrishnan, S., Palmer, J. S. \& Weaver, J. H. Size dependence of nanoparticle dissolution in a matrix: gold in bismuth. Phys. Rev. $B$ 79, 144113 (2009)

108. Briese, L., Arvidson, R. S. \& Luttge, A. The effect of crystal size variation on the rate of dissolution A kinetic Monte Carlo. Geochim. Cosmochim. Acta 212, 167-175 (2017).

109. Harker, A. B., Clarke, D. R., Jantzen, C. M. \& Morgan, P. E. D. in Surfaces and Interfaces in Ceramic and Ceramic-Metal Systems Materials Science Research (eds Pask, J. \& Evans, A.) (Springer US, New York City, 1981).

110. Myhra, S., Segall, R. L., Smart, R. S. C., Turner, P. S. \& White, T. J. Scientific basis for nuclear waste management IX. In Materials Research Society Symposium Proceedings (ed. Werme, L.O.) (Materials Research Society, Warrendale, 1985).

111. Zhang, Z. M. \& Carter, M. L. An X-ray photoelectron spectroscopy investigation of highly soluble grain-boundary impurity films in hollandite. J. Am. Ceram. Soc. 93, 894-899 (2010).

112. Oelkers, E. H. General kinetic description of multioxide silicate mineral and glass dissolution. Geochim. Cosmochim. Acta 65, 3703-3719 (2001).

113. Casey, W. H., Westrich, H. R. \& Arnold, G. W. Surface-chemistry of labradorite feldspar reacted with aqueous-solutions at $\mathrm{ph}=2,3$, and 12. Geochim. Cosmochim. Acta 52, 2795-2807 (1988).

114. Casey, W. H., Westrich, H. R., Banfield, J. F., Ferruzzi, G. \& Arnold, G. W. Leaching and reconstruction at the surfaces of dissolving chain-silicate minerals. Nature 366, 253-256 (1993).

115. Brantley, S. L. \& Chen, Y. Chemical weathering rates of pyroxenes and amphiboles. Chem. Weather Rates Silic. Miner. 31, 119-172 (1995).
116. Oelkers, E. H. \& Schott, J. An experimental study of enstatite dissolution rates as a function of $\mathrm{pH}$, temperature, and aqueous $\mathrm{Mg}$ and $\mathrm{Si}$ concentration, and the mechanism of pyroxene/pyroxenoid dissolution. Geochim. Cosmochim. Acta 65, 1219-1231 (2001)

117. Saldi, G. D., Kohler, S. J., Marty, N. \& Oelkers, E. H. Dissolution rates of talc as a function of solution composition, $\mathrm{pH}$ and temperature. Geochim. Cosmochim. Acta 71, 3446-3457 (2007).

118. Schott, J. et al. Formation, growth and transformation of leached layers during silicate minerals dissolution: the example of wollastonite. Geochim. Cosmochim. Acta 98, 259-281 (2012).

119. Angeli, F., McGlinn, P. \& Frugier, P. Chemical durability of hollandite ceramic for conditioning cesium. J. Nucl. Mater. 380, 59-69 (2008).

120. Luca, V., Cassidy, D., Drabarek, E., Murray, K. \& Moubaraki, B. Cesium extraction from $\mathrm{Ss}(0.8) \mathrm{Ba}(0.4) \mathrm{Ti}(8) \mathrm{O}(16)$ hollandite nuclear waste form ceramics in nitric acid solutions. J. Mater. Res. 20, 1436-1446 (2005).

121. Suzuki-Muresan, T., Vandenborre, J., Abdelouas, A., Grambow, B. \& Utsunomiya, $\mathrm{S}$. Studies of $(\mathrm{Cs}, \mathrm{Ba})$-hollandite dissolution under gamma irradiation at 95 degrees $C$ and at pH 2.5, 4.4 and 8.6. J. Nucl. Mater. 419, 281-290 (2011).

122. Jantzen, C. M., Clarke, D. R., Morgan, P. E. D. \& Harker, A. B. Leaching of polyphase nuclear waste ceramics - microstructural and phase characterization. J. Am. Ceram. Soc. 65, 292-300 (1982).

123. Hellmann, R. et al. Unifying natural and laboratory chemical weathering with interfacial dissolution-reprecipitation: a study based on the nanometer-scale chemistry of fluid-silicate interfaces. Chem. Geol. 294, 203-216 (2012).

124. Ruiz-Agudo, E., Putnis, C. V. \& Putnis, A. Coupled dissolution and precipitation at mineral-fluid interfaces. Chem. Geol. 383, 132-146 (2014).

125. Zhang, Z. M., Blackford, M. G., Lumpkin, G. R., Smith, K. L. \& Vance, E. R. Aqueous dissolution of perovskite $\left(\mathrm{CaTiO}_{3}\right)$ : Effects of surface damage and $\mathrm{Ca}_{2}{ }^{+}$in the leachant. J. Mater. Res. 20, 2462-2473 (2005)

126. Pham, D., Neall, F., Myhra, S., Smart, R. \& Turner, P. Dissolution mechanisms of $\mathrm{CaTiO}_{3}$ - solution analysis, surface analysis and electron microscope studies implications for synroc. MRS Proc. 127, 231-241 (1988).

127. Lumpkin, G. R. Alpha-decay damage and aqueous durability of actinide host phases in natural systems. J. Nucl. Mater. 289, 136-166 (2001).

128. Blum, A. E. in Feldspars and their Reactions (ed. Parsons, I.) (Springer, Berlin, 1994)

129. Salvi, S., Pokrovski, G. S. \& Schott, J. Experimental investigation of aluminumsilica aqueous complexing at 300 degrees C. Chem. Geol. 151, 51-67 (1998).

130. Fournier, R. O. \& Rowe, J. J. Solubility of amorphous silica in water at hightemperatures and high-pressures. Am. Mineral. 62, 1052-1056 (1977).

131. Chen, Y., Brantley, S. L. \& Ilton, E. S. X-ray photoelectron spectroscopic measurement of the temperature dependence of leaching of cations from the albite surface. Chem. Geol. 163, 115-128 (2000).

132. Sposito, G. The Surface Chemistry of Soils (Oxford University Press, Oxford, 1984).

133. Stone, A. T. \& Morgan, J. J. in Aquatic Surface Chemistry: Chemical Processes at the Particle-Water Interface (ed. Stumm, W.) 221-254 (John Wiley and Sons, Hoboken, 1987).

134. Shoesmith, D. W., Sunder, S., Bailey, M. G. \& Wallace, G. J. Anodic-oxidation of Uo2 .5. electrochemical and X-ray photoelectron spectroscopic studies of filmgrowth and dissolution in phosphate-containing solutions. Can. J. Chem. Rev. Can. Chim. 66, 259-265 (1988).

135. Shoesmith, D. W., Sunder, S., Bailey, M. G. \& Wallace, G. J. The corrosion of nuclear-fuel (uo2) in oxygenated solutions. Corros. Sci. 29, 1115-1128 (1989)

136. Jantzen, C. M. \& Trivelpiece, C. L. Uranium dissolution and geochentical modeling in anoxic and oxic solutions. MRS Adv. 2, 705-710 (2017).

137. Stumm, W. \& Furrer, G. in Aquatic Surface Chemistry: Chemical Processes at the Particle-Water Interface (ed. Stumm, W.) 197-219 (John Wiley and Sons, Hoboken, 1987).

138. Luca, V., Zhang, Y. J., Drabarek, E. \& Chronis, H. Cesium release from tungstate and titanate waste form materials in simulated canister corrosion productcontaining solutions. J. Am. Ceram. Soc. 90, 2510-2516 (2007).

139. McCafferty, E. Introduction to Corrosion Science. (Springer, Berlin, 2010).

140. Kaesche, H. Corrosion of Metals: Physicochemical Principles and Current Problems. 1st edn, 1-594 (Springer-Verlag, Berlin Heidelberg, 2003).

141. Pourbaix, M. Atlas of Electrochemical Equilibria in Aqueous Solutions. 2nd edn (National Association of Corrosion Engineers, Houston, 1974).

142. Chao, C. Y., Lin, L. F. \& Macdonald, D. D. A point-defect model for anodic passive films .1. Film growth-kinetics. J. Electrochem. Soc. 128, 1187-1194 (1981).

143. Seyeux, A., Maurice, V. \& Marcus, P. Oxide film growth kinetics on metals and alloys I. Physical model. J. Electrochem. Soc. 160, C189-C196 (2013).

144. Massoud, T. et al. Local electronic properties of the passive film on nickel studied by scanning tunneling spectroscopy. J. Electrochem. Soc. 159, C351-C356 (2012).

145. Massoud, T., Maurice, V., Klein, L. H. \& Marcus, P. Nanoscale morphology and atomic structure of passive films on stainless steel. J. Electrochem. Soc. 160, C232-C238 (2013). 
146. Seo, M., Furuichi, R., Okamoto, G. \& Sato, N. Dissolution of hydrous chromium oxide in acid solutions. Trans. Jpn Inst. Metal. 16, 519-525 (1975).

147. Mcbee, C. L. \& Kruger, J. Nature of passive films on iron-chromium alloys. Electrochim. Acta 17, 1337 (1972).

148. Kirchheim, R. et al. The passivity of iron-chromium alloys. Corros. Sci. 29, 899-917 (1989).

149. Marcus, P. \& Grimal, J. M. The anodic-dissolution and passivation of Ni-Cr-Fe alloys studied by esca. Corros. Sci. 33, 805-814 (1992).

150. Maurice, V., Yang, W. P. \& Marcus, P. XPS and STM study of passive films formed on Fe-22Cr(110) single-crystal surfaces. J. Electrochem. Soc. 143, 1182-1200 (1996).

151. Machet, A. et al. XPS and STM study of the growth and structure of passive films in high temperature water on a nickel-base alloy. Electrochim. Acta 49, 3957-3964 (2004).

152. Cabrera, N. \& Mott, N. F. Theory of the oxidation of metals. Rep. Progress. Phys. 12, 163 (1949).

153. Fehlner, F. P. \& Mott, N. F. Low-temperature oxidation. Oxid. Met. 2, 59-99 (1970).

154. Macdonald, D. D. The point-defect model for the passive state. J. Electrochem. Soc. 139, 3434-3449 (1992).

155. Momeni, M. \& Wren, J. C. A mechanistic model for oxide growth and dissolution during corrosion of Cr-containing alloys. Faraday Discuss. 180, 113-135 (2015).

156. Bojinov, M. et al. Coupling between ionic defect structure and electronic conduction in passive films on iron, chromium and iron-chromium alloys. Electrochim. Acta 45, 2029-2048 (2000).

157. Xu, Z., Rosso, K. M. \& Bruemmer, S. Metal oxidation kinetics and the transition from thin to thick films. Phys. Chem. Chem. Phys. 14, 14534-14539 (2012).

158. O'Dwyer, J. J. Theory of high field conduction in a dielectric. J. Appl. Phys. 40, 3887-3890 (1969).

159. Fromhold, A. T. Theory of Metal Oxidation: Fundamentals. (North Holland Publishing Company, Amsterdam, 1976).

160. Strehblow, H. H. Nucleation and repassivation of corrosion pits for pitting on iron and nickel. Mater. Corros. 27, 792-799 (1976).

161. Jones, D. A. Principles and Prevention of Corrosion. 2nd edn, 1-572 (Prentice-Hall, Inc., Upper Saddle River, 1996).

162. Marcus, P., Maurice, V. \& Strehblow, H. H. Localized corrosion (pitting): a model of passivity breakdown including the role of the oxide layer nanostructure. Corros. Sci. 50, 2698-2704 (2008).

163. Yu, S. Y., O'Grady, W. E., Ramaker, D. E. \& Natishan, P. M. Chloride ingress into aluminum prior to pitting corrosion - an investigation by XANES and XPS. J. Electrochem. Soc. 147, 2952-2958 (2000).

164. Macdougall, B. \& Cohen, M. Breakdown of oxide-films on nickel. J. Electrochem. Soc. 124, 1185-1190 (1977).

165. Boxley, C. J. \& White, H. S. Relationship between $\mathrm{Al}_{2} \mathrm{O}_{3}$ film dissolution rate and the pitting potential of aluminum in $\mathrm{NaCl}$ solution. J. Electrochem. Soc. 151, B265-B270 (2004).

166. Strehblow, H. H. \& Titze, B. Pitting potentials and inhibition potentials of iron and nickel for different aggressive and inhibiting anions. Corros. Sci. 17, 461-472 (1977)

167. Khalil, W., Haupt, S. \& Strehblow, H. H. The thinning of the passive layer of iron by halides. Mater. Corros. 36, 16-21 (1985).

168. Nakajima, $\mathrm{H}$. The discovery and acceptance of the Kirkendall effect: the result of a short research career. JOM 49, 15-19 (1997).

169. Wang, C.-M., Schreiber, D. K., Olszta, M. J., Baer, D. R. \& Bruemmer, S. M. Direct in situ TEM observation of modification of oxidation by the injected vacancies for Ni-4AI alloy using a microfabricated nanopost. ACS Appl. Mater. Interfaces 7, 17272-17277 (2015)

170. Luo, L. L. et al. In-situ transmission electron microscopy study of surface oxidation for $\mathrm{Ni}-10 \mathrm{Cr}$ and $\mathrm{Ni}-20 \mathrm{Cr}$ alloys. Scr. Mater. 114, 129-132 (2016).

171. Langli, L. et al. In situ atomic scale visualization of surface kinetics driven dynamics of oxide growth on a Ni-Cr surface. Chem. Commun. 52, 3300-3303 (2016).

172. Lin, L. F., Chao, C. Y. \& Macdonald, D. D. A point-defect model for anodic passive films. 2. Chemical breakdown and pit initiation. J. Electrochem. Soc. 128, 1194-1198 (1981).

173. Richardson, J. A. \& Wood, G. C. A study of pitting corrosion of a1 by scanning electron microscopy. Corros. Sci. 10, 313 (1970).

174. Sato, N. Theory for breakdown of anodic oxide films on metals. Electrochim. Acta 16, 1683 (1971).

175. Szklarska-Smialowska, Z. Pitting and Crevice Corrosion (NACE International, Houston, 2005)

176. Frankel, G. S. Pitting corrosion of metals: a review of the critical factors. J. Electrochem. Soc. 145, 2186-2198 (1998).

177. Sedriks, A. J. Corrosion of Stainless Steels 2 nd edn(John Wiley \& Sons, Hoboken, 1996).
178. Urquidi, M. \& Macdonald, D. D. Solute-vacancy interaction-model and the effect of minor alloying elements on the initiation of pitting corrosion. J. Electrochem. Soc. 132, 555-558 (1985).

179. Hashimoto, K., Asami, K. \& Teramoto, K. X-ray photoelectron spectroscopic study on the role of molybdenum in increasing the corrosion-resistance of ferritic stainless-steels in hcl. Corros. Sci. 19, 3-14 (1979).

180. Bui, N., Irhzo, A., Dabosi, F. \& Limouzinmaire, Y. ON The mechanism for improved passivation by additions of tungsten to austenitic stainless-steels. Corrosion 39, 491-496 (1983).

181. Lu, Y. C., Bandy, R., Clayton, C. R. \& Newman, R. C. Surface enrichment of nitrogen during passivation of a highly resistant stainless-steel. J. Electrochem. Soc. 130, 1774-1776 (1983).

182. Newman, R. C. \& Shahrabi, T. The effect of alloyed nitrogen or dissolved nitrate ions on the anodic behavior of austenitic stainless-steel in hydrochloric-acid. Corros. Sci. 27, 827-838 (1987).

183. Willenbruch, R. D., Clayton, C. R., Oversluizen, M., Kim, D. \& Lu, Y. AN XPS and electrochemical study of the influence of molybdenum and nitrogen on the passivity of austenitic stainless-steel. Corros. Sci. 31, 179-190 (1990).

184. Brigham, R. J. \& Tozer, E. W. Localized corrosion-resistance of mn-substituted austenitic stainless-steels - effect of molybdenum and chromium. Corrosion 32, 274-276 (1976).

185. Frankel, G. S., Stockert, L., Hunkeler, F. \& Boehni, H. Metastable pitting of stainless steel. Corrosion 43, 429-436 (1987).

186. Salinasbravo, V. M. \& Newman, R. C. AN alternative method to determine critical pitting temperature of stainless-steels in ferric-chloride solution. Corros. Sci. 36, 67-77 (1994).

187. Qvarfort, R. Critical pitting temperature-measurements of stainless-steels with an improved electrochemical method. Corros. Sci. 29, 987-993 (1989).

188. Moayed, M. H., Laycock, N. J. \& Newman, R. C. Dependence of the critical pitting temperature on surface roughness. Corros. Sci. 45, 1203-1216 (2003).

189. Brigham, R. J. \& Tozer, E. W. Temperature as a pitting criterion. Corrosion 29, 33-36 (1973).

190. Alkire, R. C. \& Wong, K. P. The corrosion of single pits on stainless-steel in acidic chloride solution. Corros. Sci. 28, 411 (1988).

191. Hunkeler, F. \& Bohni, H. Determination of pit growth-rates on aluminum using a metal foil technique. Corrosion 37, 645-650 (1981).

192. Newman, R. C. \& Franz, E. M. Growth and repassivation of single corrosion pits in stainless-steel. Corrosion 40, 325-330 (1984).

193. Kondo, Y. Prediction of fatigue crack initiation life based on pit growth. Corrosion 45, 7-11 (1989).

194. Frankel, G. S., Li, T. S. \& Scully, J. R. Localized corrosion: passive film breakdown vs pit growth stability. J. Electrochem. Soc. 164, C180-C181 (2017).

195. Oh, K., Ahn, S., Eom, K., Jung, K. \& Kwon, H. Observation of passive films on Fe$20 \mathrm{Cr}-x \mathrm{Ni}(x=0,10,20$ wt.\%) alloys using TEM and Cs-corrected STEM-EELS. Corros. Sci. 79, 34-40 (2014).

196. $\mathrm{Xu}, \mathrm{H}$. F. et al. Investigation of pyrochlore-based U-bearing ceramic nuclear waste: uranium leaching test and TEM observation. Environ. Sci. Technol. 38, 1480-1486 (2004).

197. Neeway, J. J., Rieke, P. C., Parruzot, B. P., Ryan, J. V. \& Asmussen, R. M. The dissolution behavior of borosilicate glasses in far-from equilibrium conditions. Geochim. Cosmochim. Acta 226, 132-148 (2018).

198. Guy, C. et al. New conditionings for separated long-lived radionuclides. Comptes Rendus Phys. 3, 827-837 (2002).

199. Roberts, S. K., Bourcier, W. L. \& Shaw, H. F. Aqueous dissolution kinetics of pyrochlore, zirconolite and brannerite at 25, 50, and 75 degrees C. Radiochim. Acta 88, 539-543 (2000).

200. Frankel, G. S. et al. Repassivation transients measured with thin-film breaking electrodes. J. Electrochem. Soc. 138, 643-644 (1991).

201. Kolman, D. G. \& Scully, J. R. Limitations of potentiostatic repassivation techniques and their relationship to the applicability of the high-field approximation to the repassivation of titanium. J. Electrochem. Soc. 142, 2179-2188 (1995).

202. Peters, R. D. \& Slate, S. C. Fracturing of simulated high-level waste glass in canisters. Nucl. Eng. Des. 67, 425-445 (1982).

203. Kim, D.-S., Peeler, D. K. \& Hrma, P. Effect of crystallization on the chemical durability of simulated nuclear waste glasses. Ceram. Trans. 61, 177-186 (1995).

204. Cammarata, R. C. Surface and interface stress effects in thin-films. Prog. Surf. Sci. 46, 1-38 (1994).

205. Luo, J., Zhou, Y., Milner, S. T., Pantano, C. G. \& Kim, S. H. Molecular dynamics study of correlations between IR peak position and bond parameters of silica and silicate glasses: Effects of temperature and stress. J. Am. Ceram. Soc. 101, 178-188 (2018).

206. Sheth, N., Luo, J. W., Banerjee, J., Pantano, C. G. \& Kim, S. H. Characterization of surface structures of dealkalized soda lime silica glass using $\mathrm{X}$-ray photoelectron, specular reflection infrared, attenuated total reflection infrared and sum frequency generation spectroscopies. J. Non-Cryst. Solids 474, 24-31 (2017). 
207. Du, J. \& Rimsza, J. Atomistic computer simulations of water interactions and dissolution of inorganic glasses. Nat. Mat. Deg. 1, 16 (2017).

208. Criscenti, L. J., Kubicki, J. D. \& Brantley, S. L. Silicate glass and mineral dissolution: calculated reaction paths and activation energies for hydrolysis of a $\mathrm{Q}(3)$ si by H3O+using ab initio methods. J. Phys. Chem. A 110, 198-206 (2006).

209. Greeley, J. \& Norskov, J. K. Electrochemical dissolution of surface alloys in acids: Thermodynamic trends from first-principles calculations. Electrochim. Acta 52, 5829-5836 (2007).

210. Taylor, C. D., Neurock, M. \& Scully, J. R. First-principles investigation of the fundamental corrosion properties of a model $\mathrm{Cu}(38)$ nanoparticle and the (111), (113) surfaces. J. Electrochem. Soc. 155, C407-C414 (2008).

211. Mathew, K., Sundararaman, R., Letchworth-Weaver, K., Arias, T. A. \& Hennig, R. G. Implicit solvation model for density-functional study of nanocrystal surfaces and reaction pathways. J. Chem. Phys. 140, 084106 (2014).

212. Yuwono, J. A., Birbilis, N., Williams, K. S. \& Medhekar, N. V. Electrochemica stability of magnesium surfaces in an aqueous environment. J. Phys. Chem. C. 120, 26922-26933 (2016).

213. Bourcier, W. L. Waste glass corrosion modeling: comparison with experimental results. In Materials Research Society Symposium Proceedings (Materials Research Society, Warrendale, 2011).

214. Mishra, B., Al-Hassan, S., Olson, D. L. \& Salama, M. M. Development of a predictive model for activation-controlled corrosion of steel in solutions containing carbon dioxide. Corrosion 53, 852-859 (1997).

215. Delaye, J. M. \& Ghaleb, D. Molecular dynamics simulation of $\mathrm{SiO}_{2}+\mathrm{B}_{2} \mathrm{O}_{3}+\mathrm{Na}_{2} \mathrm{O}$ $+\mathrm{ZrO}_{2}$ glass. J. Non-Cryst. Solids 195, 239-248 (1996).

216. Ren, M. G., Deng, L. \& Du, J. C. Bulk, surface structures and properties of sodium borosilicate and boroaluminosilicate nuclear waste glasses from molecular dynamics simulations. J. Non-Cryst. Solids 476, 87-94 (2017).

217. Ren, M. G., Deng, L. \& Du, J. C. Surface structures of sodium borosilicate glasses from molecular dynamics simulations. J. Am. Ceram. Soc. 100, 2516-2524 (2017)

218. Collin, M. et al. Structure of International Simple Glass and properties of passivating layer formed in circumneutral $\mathrm{pH}$ conditions. npj Mater. Degrad. 2, 4 (2018).
219. Rimsza, J. M. \& Du, J. C. Interfacial structure and evolution of the water-silica gel system by reactive force-field-based molecular dynamics simulations. J. Phys. Chem. C. 121, 11534-11543 (2017).

220. Rimsza, J. M., Yeon, J., van Duin, A. C. T. \& Du, J. C. Water interactions with nanoporous silica: comparison of ReaxFF and ab Initio based molecular dynamics simulations. J. Phys. Chem. C. 120, 24803-24816 (2016).

221. Assowe, O. et al. Reactive molecular dynamics of the initial oxidation stages of $\mathrm{Ni}(111)$ in pure water: effect of an applied electric field. J. Phys. Chem. A 116, 11796-11805 (2012)

222. Malki, B. \& Baroux, B. Computer simulation of the corrosion pit growth. Corros. Sci. 47, 171-182 (2005).

223. Kerisit, S., Pierce, E. M. \& Ryan, J. V. Monte Carlo simulations of coupled diffusion and surface reactions during the aqueous corrosion of borosilicate glasses. J. Non-Cryst. Solids 408, 142-149 (2015).

224. Ledieu, A., Devreux, F. \& Barboux, P. Monte Carlo simulations of borosilicate glass corrosion: predictions for morphology and kinetics. J. Non-Cryst. Solids $\mathbf{3 4 5}$, 715-719 (2004).

Open Access This article is licensed under a Creative Commons Attribution 4.0 International License, which permits use, sharing, adaptation, distribution and reproduction in any medium or format, as long as you give appropriate credit to the original author(s) and the source, provide a link to the Creative Commons license, and indicate if changes were made. The images or other third party material in this article are included in the article's Creative Commons license, unless indicated otherwise in a credit line to the material. If material is not included in the article's Creative Commons license and your intended use is not permitted by statutory regulation or exceeds the permitted use, you will need to obtain permission directly from the copyright holder. To view a copy of this license, visit http://creativecommons. org/licenses/by/4.0/.

(c) The Author(s) 2018 